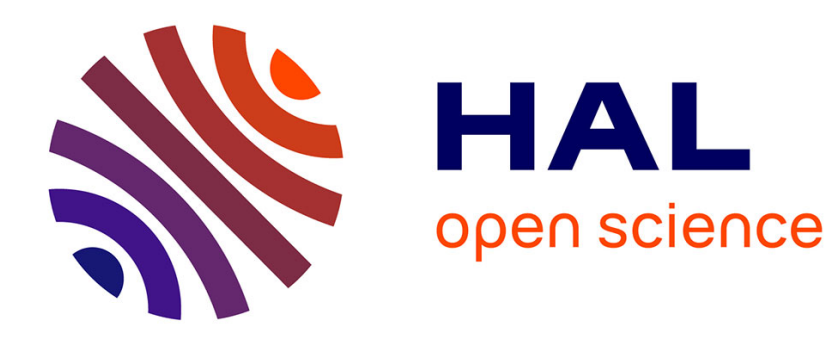

\title{
Nouvelles techniques de réalisation de photopiles au silicium
}

P. Siffert

\section{To cite this version:}

P. Siffert. Nouvelles techniques de réalisation de photopiles au silicium. Revue de Physique Appliquée, 1979, 14 (1), pp.169-192. 10.1051/rphysap:01979001401016900 . jpa-00244574

\section{HAL Id: jpa-00244574 https://hal.science/jpa-00244574}

Submitted on 1 Jan 1979

HAL is a multi-disciplinary open access archive for the deposit and dissemination of scientific research documents, whether they are published or not. The documents may come from teaching and research institutions in France or abroad, or from public or private research centers.
L'archive ouverte pluridisciplinaire HAL, est destinée au dépôt et à la diffusion de documents scientifiques de niveau recherche, publiés ou non, émanant des établissements d'enseignement et de recherche français ou étrangers, des laboratoires publics ou privés. 


\title{
Nouvelles techniques de réalisation de photopiles au silicium
}

\author{
P. Siffert \\ Centre de Recherches Nucléaires \\ Groupe de Physique et Applications des Semiconducteurs (PHASE) \\ 67037 Strasbourg-Cedex, France
}

(Reçu le 12 juin 1978, révisé le 31 octobre 1978, accepté le 31 octobre 1978)

\begin{abstract}
Résumé. - Dans cet article on passe en revue les différentes méthodes d'élaboration des cellules solaires terrestres à base de silicium (sans concentration lumineuse). En partant des méthodes actuelles d'élaboration du silicium et des jonctions, on analyse les progrès possibles. Puis, l'accent est mis sur les voies nouvelles explorées actuellement pour l'obtention de silicium mono ou polycristallin en couches minces. Puis, on s'intéresse aux différents procédés, non conventionnels, mis en œuvre pour la réalisation de la barrière de potentiel.
\end{abstract}

\begin{abstract}
In this article, the various methods used to prepare terrestrial silicon solar cells are reviewed (cells without sun concentration). Starting from the currently available process to manufacture both the material and the junction, the possible improvements are discussed. Then, the new approaches to prepare either mono or polycristalline silicon sheets are considered in some detail. Finally, non conventional methods to realize the junction barrier are investigated.
\end{abstract}

Introduction. - Comparée aux autres sources d'énergie, l'électricité produite par des cellules photovoltaïques est actuellement trop onéreuse pour les applications terrestres à grande échelle. De ce fait, les cellules solaires, qui sont, à de rares exceptions près, à base de silicium, sont limitées actuellement aux applications spatiales ou à des installations terrestres en sites isolés, pour lesquelles le coût ne constitue pas un élément prédominant (balises de guidage d'avions...) mais où les sources conventionnelles d'énergie font défaut (télévision, pompage d'eau...). L'énergie d'origine solaire ne pourra donc devenir compétitive qu'au prix d'une réduction très sensible des coûts, le seuil de rentabilité variant évidemment avec le lieu et l'emploi envisagé. Cet objectif pourra être essentiellement atteint de deux façons :

- soit par simple accroissement du volume à partir de technologies existantes, par une évolution bien connue des prix des dispositifs semiconducteurs (transistors, calculatrices...), lorsque les quantités fabriquées augmentent;

- soit à partir de technologies nouvelles d'élaboration des matériaux et des dispositifs.

On pense généralement qu'une optimalisation des méthodes conventionnelles permettra des réductions de coût notables jusque vers 1983-85 (Fig. 1), suivie de la commercialisation de cellules préparées suivant des procédés nouveaux.

L'objectif de cet exposé est de passer en revue les principales filières envisagées à l'heure actuelle en

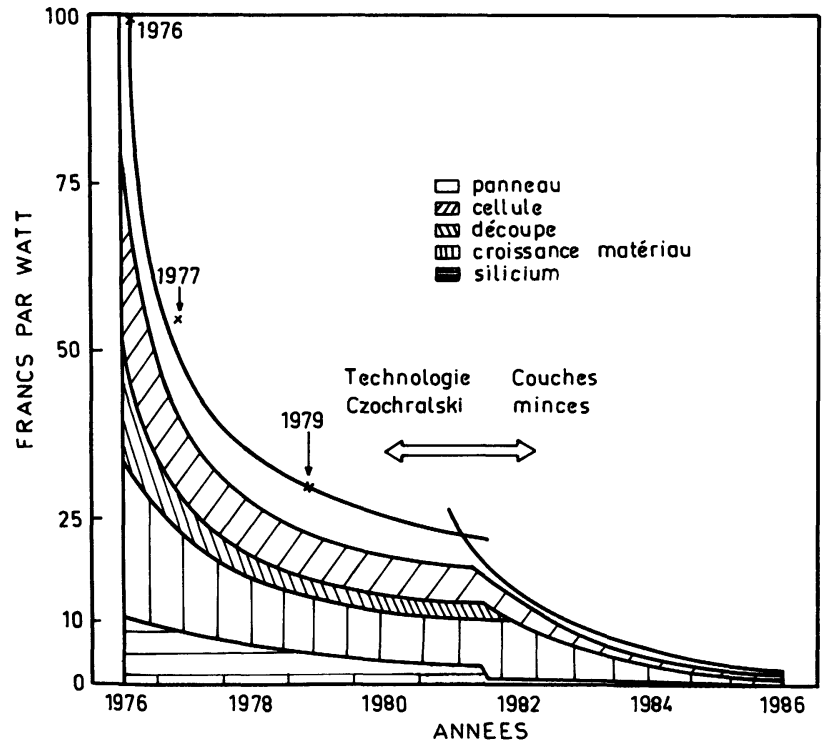

Fig. 1. - Estimation ERDA de l'évolution du prix du watt crête d'électricité photovoltaïque [192] en valeur 1975.

[Peak watt cost for photovoltaic electricity as estimated for the future by ERDA [192] in 1975 value.]

partant de silicium. Nous nous limiterons aux cellules opérant sans concentration lumineuse, non parce que l'intérêt des autres est moindre, mais parce que les technologies mises en œuvre sont souvent différentes et plus complexes. De plus, nous négligerons volontairement les problèmes d'encapsulation pour 
lesquels nous ne sommes pas qualifiés, mais qui représentent environ $1 / 3$ du prix de revient du dispositif.

Dans une première partie de cet exposé, nous nous intéresserons aux photopiles actuelles à base de silicium monocristallin massif, puis nous étudierons quelques évolutions possibles. Dans une deuxième partie, nous analyserons certaines méthodes proposées récemment pour l'obtention du matériau, essentiellement en films mono- ou polycristallins voire amorphe. Dans une dernière partie, nous aborderons les méthodes nouvelles de réalisation de la barrière de potentiel nécessaire à une bonne collecte des photoporteurs.

1. Cellules actuelles à base de silicium monocristallin. - Les panneaux solaires proposés par les divers fabricants présentent des différences d'aspect notables quant à leur taille ou à l'interconnexion des cellules individuelles qui les constituent, mais ces dernières sont très voisines (Fig. 2). En effet, elles sont formées de jonctions P-N obtenues par diffusion d'impuretés dans le silicium monocristallin (découpé préalab̄lement en tranches) de type $P$ et de haute pureté (qualité électronique). Les diamètres des cellules sont généralement compris entre $50-100 \mathrm{~mm}$ et les épaisseurs de plaquettes sont de 0,2-0,4 mm. Les
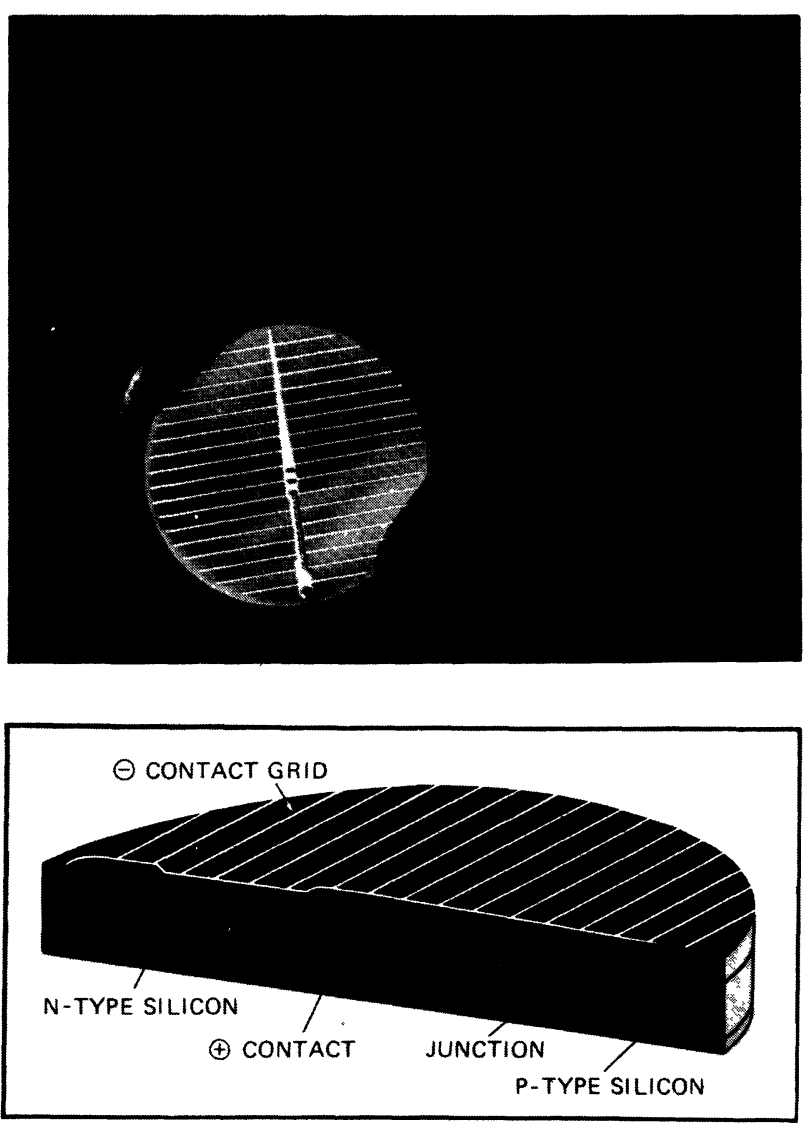

Fig. 2. - Exemple de cellule photovoltaïque $\varnothing 100 \mathrm{~mm}$ (RTC). Contact grid $=$ grille de contact, + contact $=$ contact ohmique.

[Typical solar cell $100 \mathrm{~mm}$ in diameter (RTC).] rendements de conversion sont voisins de $10-13 \%$. Comme on pourra le constater sur les figures $3 a$ et $b$ les diverses étapes de préparation du silicium monocristallin puis des jonctions diffusées sont identiques à celles employées traditionnellement pour la préparation de diodes et transistors. Il n'est donc pas étonnant que le coût des cellules actuelles soit élevé, l'industrie n'ayant fait qu'appliquer des technologies qu'elle maîtrise bien par ailleurs. Examinons d'un peu plus près ces diverses étapes.

ELABORATION DU SILICIUM MONOCRISTALLIN

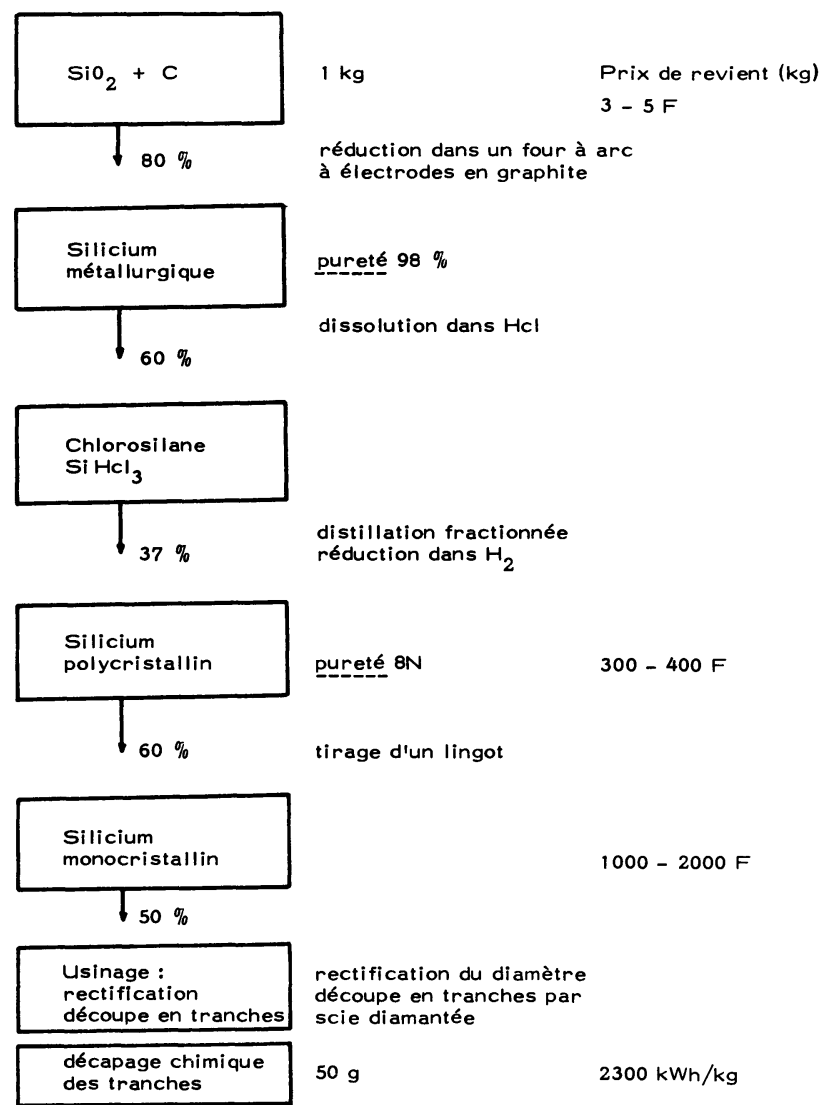

Fig. $3 a$. - Etapes essentielles dans l'élaboration de silicium monocristallin à partir de la silice. Notez qu'en partant de $1 \mathrm{~kg}$ de matière première on n'obtient que $50 \mathrm{~g}$ de plaquettes monocristallines.

[Preparation procedure of single crystal silicon starting from $\mathrm{SiO}_{2}$.]

1.1 MatéRIAU De base : Silicium. - 1.1.1 Purification. - De nombreuses méthodes ont été publiées dans la littérature [1-5], nous nous limiterons aux étapes essentielles. On sait depuis le début du siècle préparer le silicium de qualité métallurgique par chauffage au four électrique d'un mélange de sable (très riche en silicium) et de coke [6], suivant les réactions :

$$
\begin{aligned}
& \mathrm{SiO}_{2}+2 \mathrm{C} \rightarrow \mathrm{Si}+2 \mathrm{CO} \\
& \mathrm{SiO}_{2}+3 \mathrm{C} \rightarrow \mathrm{SiC}+2 \mathrm{CO} \\
& \mathrm{SiO}_{2}+2 \mathrm{SiC} \rightarrow 3 \mathrm{Si}+2 \mathrm{CO} .
\end{aligned}
$$



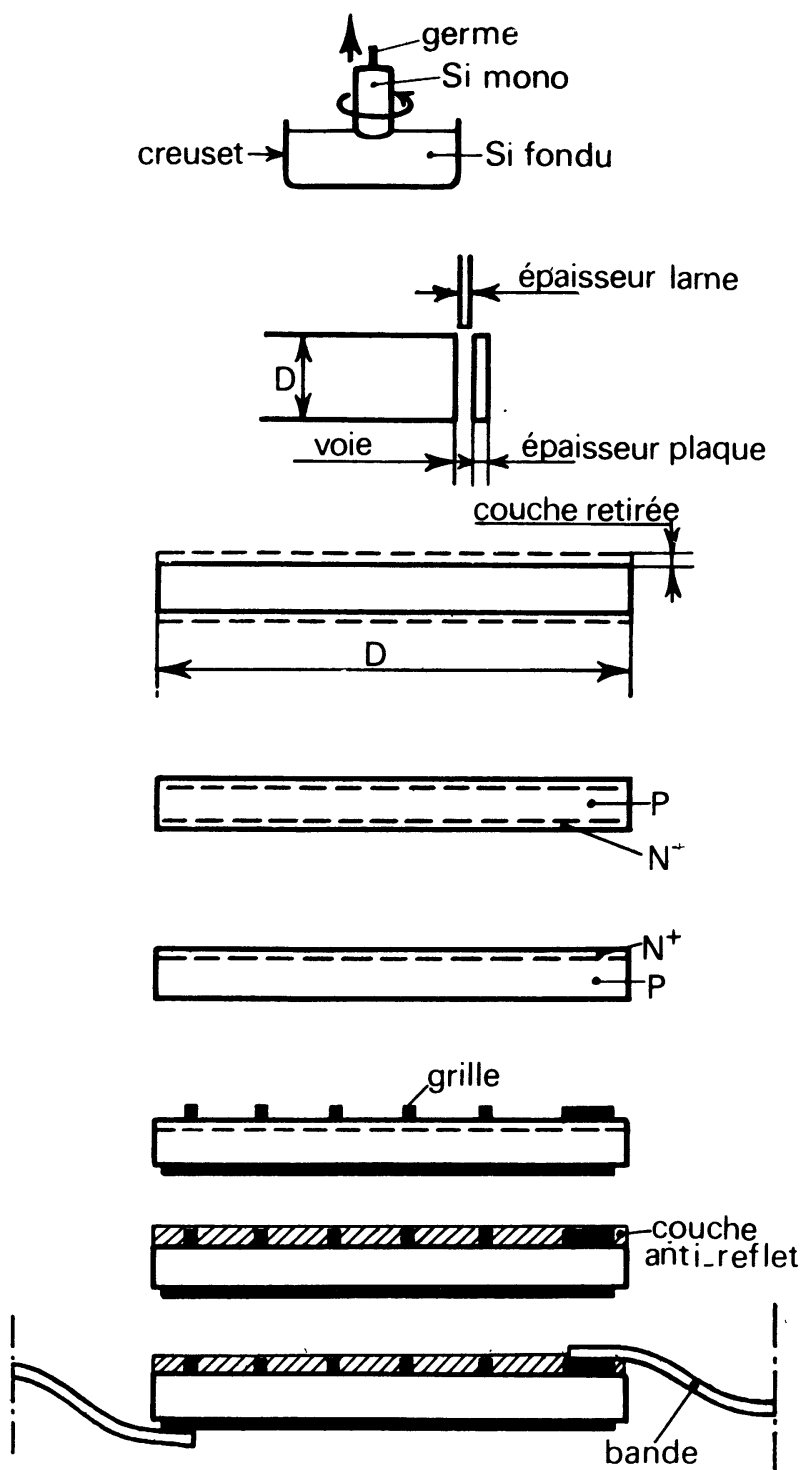

ou grille métallique

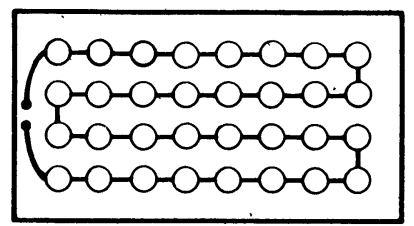

Fig. $3 b$. - Principales étapes dans la fabrication d'une photopile au silicium [193]. Après croissance du monocristal, des plaquettes d'épaisseur 250-500 $\mu$ sont découpées, ces dernières sont rôdées puis diffusées et finalement recouvertes d'une grille de collecte et d'un film anti-réfléchissant.

[Main steps in the realization of a junction photocell by diffusion.]

Toutefois, la pureté $(98 \%)$ de ce matériau ne permet pas son emploi à la réalisation de cellules car la concentration élevée d'impuretés entraîne d'une part une densité trop forte de niveaux de recombinaison et de piégeage électriquement actifs qui vont retenir les porteurs photogénérés, d'autre part rend difficile la monocristallisation, puisque les impuretés constituent des sites de nucléation préférentiels.
Afin de purifier ce silicium métallurgique on le traite à l'acide chlorhydrique anhydre vers $250^{\circ} \mathrm{C}$ pour former un composé gazeux, plus facile à purifier, le trichlorosilane $\mathrm{SiHCl}_{3}$. Après distillation fractionnée, ce dernier est réduit par l'hydrogène vers $1000^{\circ} \mathrm{C}$ pour former finalement le silicium de qualité électronique, de pureté $8 \mathrm{~N}$. Les réactions chimiques en jeu sont complexes, les plus probables étant :

$$
\begin{aligned}
& 4 \mathrm{SiHCl}_{3} \rightarrow \mathrm{Si}+3 \mathrm{SiCl}_{4}+2 \mathrm{H}_{2} \\
& \mathrm{SiCl}_{4}+\mathrm{H}_{2} \rightarrow \mathrm{SiHCl}_{3}+\mathrm{HCl} \\
& \mathrm{SiHCl}_{3}+\mathrm{H}_{2} \rightarrow \mathrm{Si}+3 \mathrm{HCl}
\end{aligned}
$$

1.1.2 Tirage du monocristal. - La monocristallisation est effectuée essentiellement par les méthodes conventionnelles de zone flottante ou Czockralski. Dans cette dernière, par exemple, le matériau est fondu et dopé par du bore à des concentrations de $10^{16}$ $10^{17} \mathrm{~cm}^{-3}(0,1-1 \Omega . \mathrm{cm})$. Dans un gradient de température convenable, un germe monocristallin correctement orienté facilitera la nucléation sur ses faces cristallographiques d'atomes provenant du bain. Finalement, un monocristal sera obtenu. A l'heure actuelle des cristaux de diamètre $100 \mathrm{~mm}$ sont couramment préparés à des vitesses de $10-15 \mathrm{~cm} / \mathrm{h}$, leur longueur peut dépasser le mètre. Des systèmes d'asservissement jouant sur le gradient thermique permettront la croissance de lingots quasi cylindriques à diamètre constant.

1.1.3 Découpe en tranches. - La tête et la queue des lingots constituent des zones perturbées qu'il faut éliminer sur des longueurs égales à peu près au diamètre du cristal. La découpe en plaquettes d'épaisseur 300-500 $\mu$ s'effectue ensuite à l'aide d'une scie munie d'une lame diamantée ayant une voie de 300 $400 \mu$, tournant à grande vitesse avec un avancement de l'ordre de $10 \mathrm{~cm} / \mathrm{min}$. La moitié au moins du monocristal est donc perdue !

Les défauts de structure introduits en surface lors de la découpe sont éliminés par rôdage mécanique suivi d'un décapage chimique, l'épaisseur enlevée étant de l'ordre de $25 . \mu$.

1.2 RÉalisation De LA CELlule. - La barrière de potentiel nécessaire à la collecte des porteurs photogénérés est obtenue dans tous les dispositifs commerciaux par diffusion thermique d'impuretés de type $\mathbf{N}$, le plus souvent de phosphore. Généralement, un gaz comportant l'impureté circule dans un tube de quartz porté à haute température $\left(800-1100^{\circ} \mathrm{C}\right)$, où sont placées les plaquettes de silicium préalablement décapées. La diffusion obéit aux lois de Fick et produit une jonction $N^{+}-\mathrm{P}$ localisée à $0,2-1 \mu$ de la surface, la concentration superficielle de dopants $\left(\approx 10^{20} \mathrm{~cm}^{-3}\right)$ étant limitée par la solubilité à la température de diffusion, conduit à une résistance superficielle de l'ordre de 30-100 $\Omega / \square$.

Cette étape jouera un rôle déterminant sur les performances de la cellule. En effet, une profondeur 
de diffusion faible (d'où la nécessité de fours à température très uniforme) conduit à une fenêtre d'entrée réduite, donc à une meilleure réponse en U.V. et un accroissement du rendement de conversion, par contre, elle entraîne une résistance superficielle plus importante donc une perte de puissance, qui peut, toutefois, être partiellement compensée par un peigne plus fin. De plus, il convient de noter que la diffusion thermique entraîne par ailleurs :

- une dégradation certaine des longueurs de diffusion par suite du choc thermique;

- le recours à de nombreux traitements chimiques de décapage : comme la diffusion s'opère sur toutes les faces des plaquettes il est nécessaire de décaper toutes les surfaces exceptée celle servant à former la jonction. Pour ce faire, il faudra masquer cette face, dissoudre une partie des autres surfaces, enlever le masque et nettoyer l'ensemble. Sur la face arrière, il est ensuite nécessaire de réaliser un contact ohmique soit par diffusion thermique d'une impureté $P$, ou par dépôt d'une couche métallique éventuellement suivi d'un cycle thermique pour former un alliage.

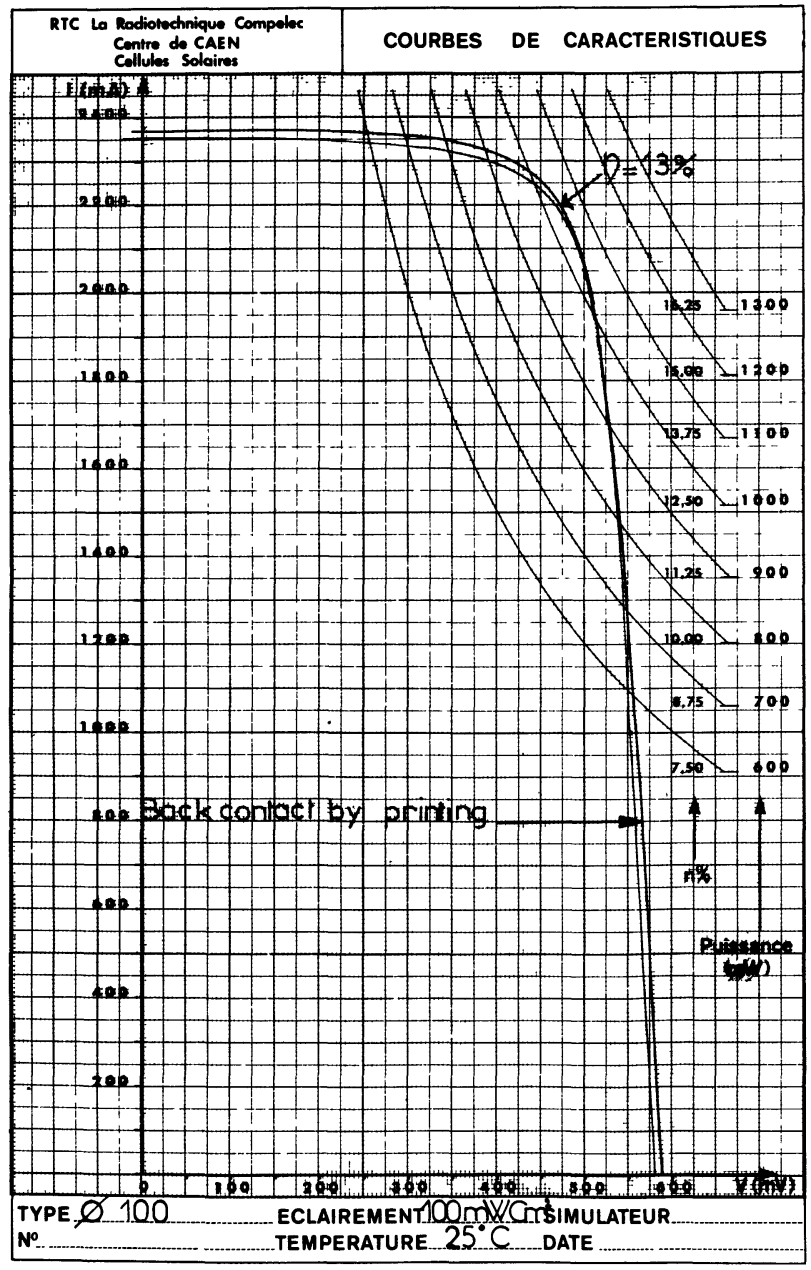

Fig. 4. - Caractéristique courant-tension sous éclairement $\left(100 \mathrm{~mW} / \mathrm{cm}^{2}\right)$ d'une photopile au silicium $\varnothing 100 \mathrm{~mm}[9]$.

[Typical $I-V$ characteristic under AM1 illumination for a $100 \mathrm{~mm}$ in diameter silicon diffused cell [9].]
Pour que la collecte des porteurs puisse se faire efficacement il faudra disposer des grilles métalliques sur la jonction en ayant soin de minimiser leur aire totale, tout en assurant une bonne évacuation des photoporteurs.

Finalement, il est nécessaire de recouvrir la face avant de la cellule d'une couche anti-reflets, car l'indice de réfraction élevé du silicium $(\approx 3,5)$ entraîne une réflexion de $35 \%$ environ de la lumière solaire. Une meilleure absorption sera obtenue par dépôt d'un composé à indice faible $\mathrm{SiO}_{2}$ et surtout $\mathrm{TiO}_{2}$ d'épaisseur voisine de $500 \AA$.

Cette technologie conduit à des cellules ayant une courbe $I-V$ sous éclairement voisine de celle de la figure 4 [9].

1.3 Evolution POSSIBle DE CETTE FILIÈre. 1.3.1 Diminution des coûts de la matière première. L'élaboration du matériau, la réalisation de la jonction, l'encapsulation contribuent à parties égales au prix d'une cellule. Une réduction des coûts passera donc par des améliorations importantes dans ces trois étapes.

- Croissance des monocristaux. - Pour une vitesse de tirage donnée, la production croîtra rapidement avec le diamètre des lingots. Il en résultera une diminution de coût, comme on a pu le constater dans le passé non seulement au tirage mais encore au traitement des plaquettes. Cette tendance se poursuivra et après les lingots de $\varnothing 25-50 \mathrm{~mm}$, des diamètres de plus de $10 \mathrm{~cm}$ sont envisagés. Il convient de noter que cela entraînera des problèmes technologiques nouveaux liés au poids élevé de ces monocristaux (plusieurs dizaines de $\mathrm{kg}$ ) et à la difficulté de maintenir les gradients thermiques convenables. Pour éviter de maintenir une grande masse de silicium en fusion, celui-ci devrait être introduit progressivement en cours de tirage, ce qui risque de provoquer quelques perturbations. De plus, pour éviter les pertes en tête et queue des lingots (égales au diamètre du cristal) il faudra modifier les méthodes de tirage [9] (Fig. 5). On peut penser que des installations de conception nouvelle seront nécessaires.
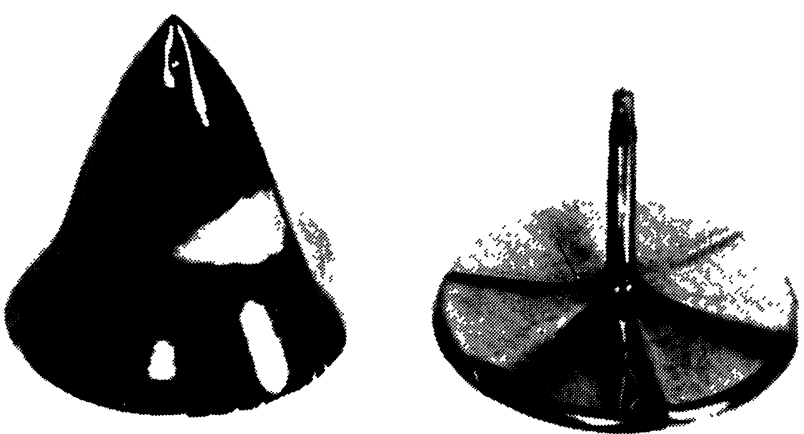

Fig. 5. - Cône de début de croissance d'un lingot de silicium monocristallin obtenu par la procédure classique (à gauche) et la méthode du cồne plat [193].

[Shape of the silicon single crystals for two different growth conditions [193].] 
- Croissance à partir de silicium moins purifié. Jusqu'ici on a employé pour la croissance des cristaux destinés aux cellules solaires uniquement du silicium très purifié, identique à celui utilisé dans l'industrie électronique. On peut se demander si un matériau moins pur ne pourrait pas convenir. Des essais dans ce sens sont actuellement en cours dans plusieurs laboratoires [9-18] et il semble qu'un silicium de qualité solaire pouvant contenir jusqu'à $10^{16}-10^{17}$ impuretés $/ \mathrm{cm}^{3}$ puisse conduire à des cellules de rendement $10 \%$, seuil de rentabilité pour toute cellule. Des estimations plus précises de taux acceptables pour quelques impuretés sont reportées sur la figure 6 . Ces impuretés chimiques interviennent de deux manières :

- d'une part elles introduisent des centres de piégeage et de recombinaison, ce qui conduit à une dégradation des longueurs de diffusion des por-
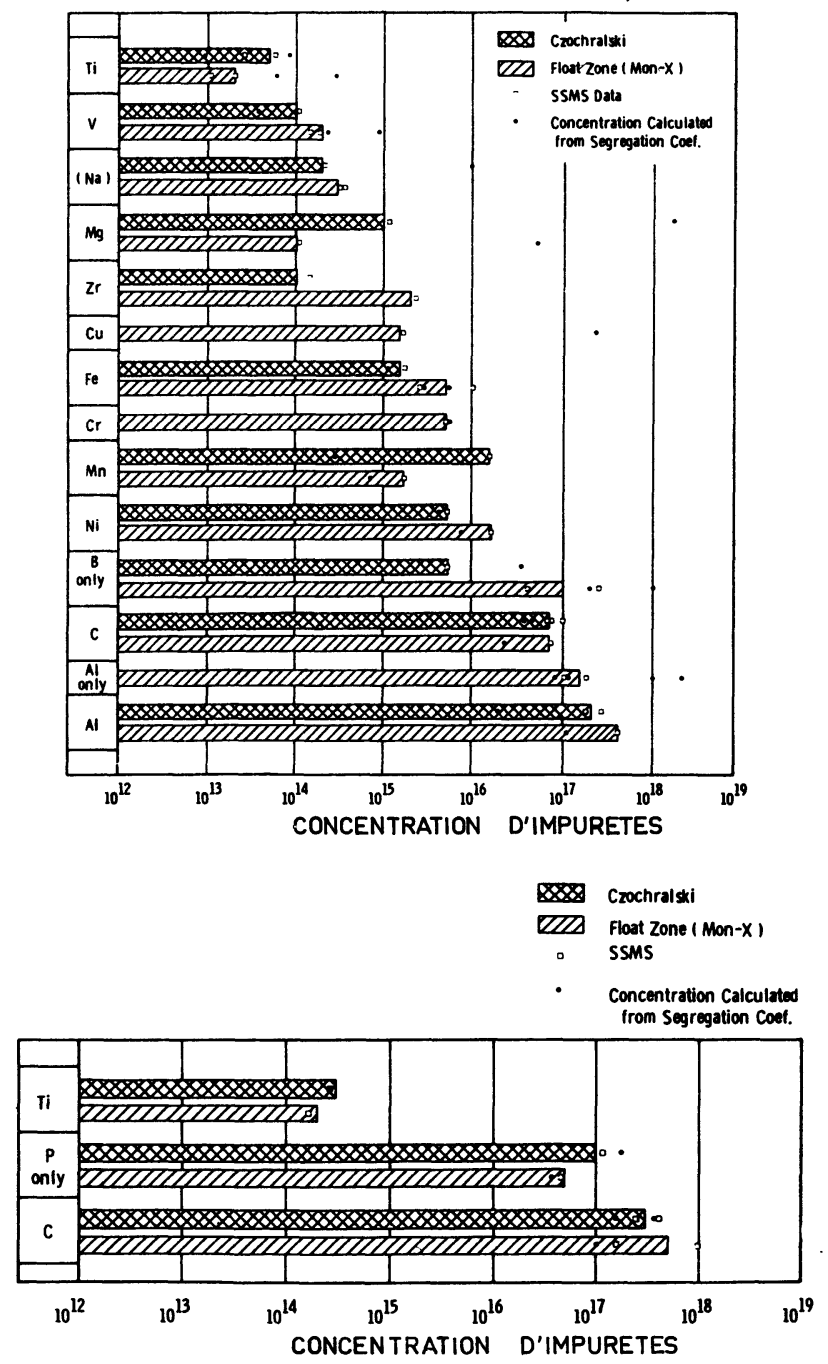

Fig. 6. - Estimation des concentrations d'impuretés acceptables dans le silicium de résistivité $0,5 \Omega$. cm dopé au bore (haut) ou au phosphore (bas) pour atteindre des rendements de conversion de $10 \%$ [10].

[Estimate of the permissible concentration of secondary impurities in $0.5 \Omega$.cm boron doped silicon, which will still permit a $10 \%$ efficiency cell to be fabricated [10].] teurs, qui affectera directement le rendement de conversion (Fig. 7);

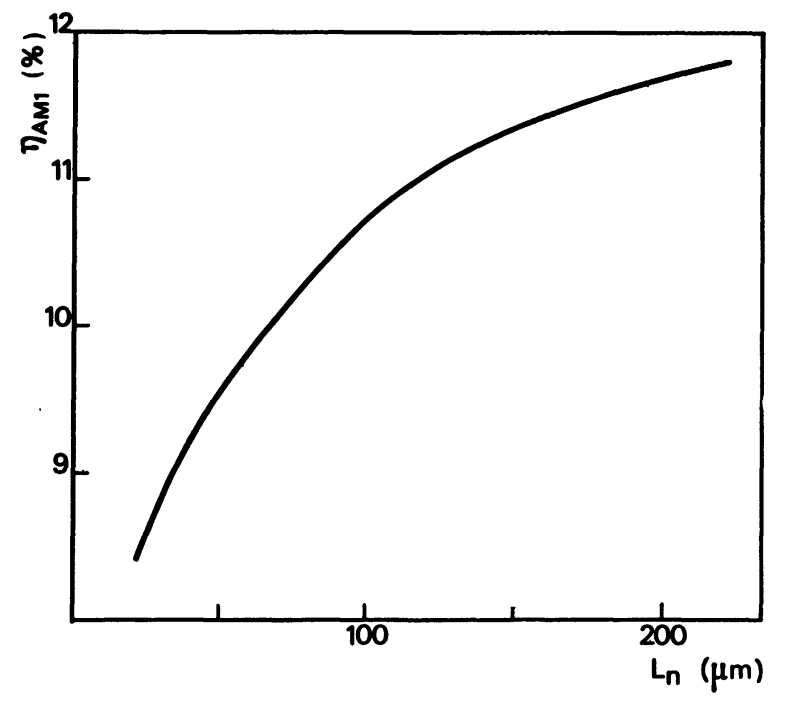

Fig. 7. - Rendement théorique de conversion sous éclairement AM1 en fonction de la longueur de diffusion des porteurs minoritaires pour une structure $\mathrm{N}^{+} / \mathbf{P}$ d'épaisseur $250 \mu$ de profondeur de jonction $0,2 \mu$ et de concentration d'accepteurs $N_{\mathrm{a}}=10^{16} \mathrm{~cm}^{-3}$ [193].

[Calculated conversion efficiency as a function of minority carrier diffusion length under AM1 illumination for a $\mathbf{N}^{+} / \mathrm{P}$ cell having a total thickness of $250 \mu$, a junction depth of $0.2 \mu$ and an acceptor carrier concentration of $N_{\mathrm{a}}=10^{-16} \mathrm{~cm}^{-3}$ [193].]

- d'autre part, elles jouent le rôle de centres de nucléation lors de la cristallogenèse du silicium, ce qui entraînera la croissance de polycristaux.

- Découpe. - Nous avons pu constater plus haut que dans les technologies actuelles la moitié du monocristal était perdue en cours d'usinage. Il est évidemment souhaitable d'améliorer cette situation. Une première possibilité est de réduire l'épaisseur des lames de scie, mais cela pose de sérieux problèmes, nécessitant également la mise au point de nouvelles méthodes de sciage. Par ailleurs, on peut réduire l'épaisseur des plaquettes, dont l'effet est notable sur les coûts [9].

En plus des problèmes liés à la fragilité des plaquettes minces, il est nécessaire de connaître l'effet d'une réduction d'épaisseur sur le rendement de conversion. Des simulations à l'ordinateur [15] ont permis de montrer (Fig. 8) l'influence de l'épaisseur sur le rendement tant pour les jonctions $\mathrm{N}^{+}-\mathrm{P}$ simples que pour les diodes $\mathrm{N}^{+}-\mathrm{P}-\mathrm{P}^{+}$munies également d'une jonction à la face arrière (back surface field). Cette dernière produit une barrière de potentiel renvoyant les porteurs photogénérés vers la zone de charge d'espace et les empêchant ainsi de se recombiner [16].

Récemment, on [17] a obtenu des cellules d'épaisseur $50 \mu$ ayant un rendement de $14 \%$ (AM1); toutefois ces cellules étaient préparées par dissolution chimique de plaquettes plus épaisses dans un bain de 


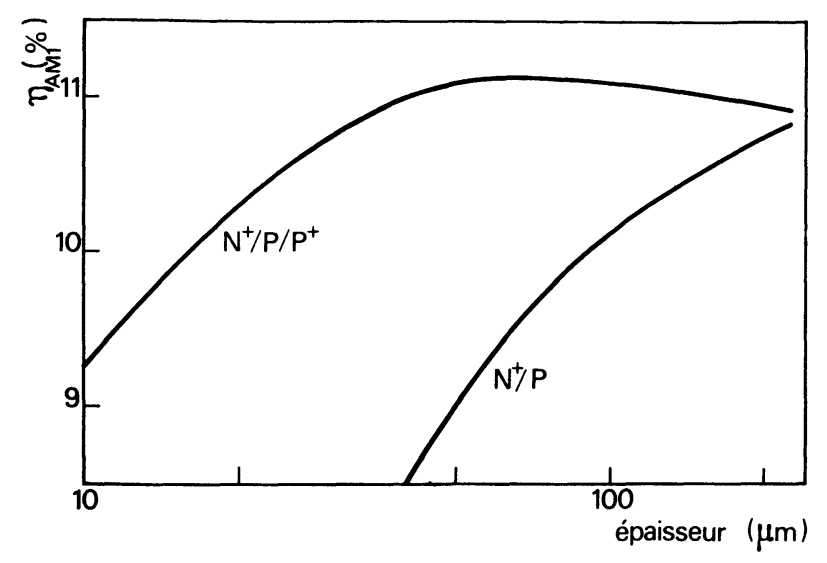

Fig. 8. - Rendement théorique de conversion en fonction de l'épaisseur de la photopile pour une structure $\mathrm{N}^{+} / \mathrm{P}$ et $\mathrm{N}^{+} / \mathbf{P} / \mathrm{P}^{+}$, de profondeur de diffusion $0,2 \mu$, de longueur de diffusion $108 \mu$, sous éclairement AM1 pour une concentration d'accepteurs $N_{\mathrm{a}}=10^{16} \mathrm{~cm}^{-3}[193]$

[Calculated conversion efficiency as a function of total cell thickness for both $\mathbf{N}^{+} / \mathbf{P}$ and $\mathrm{N}^{+} / \mathbf{P} / \mathbf{P}^{+}$(back surface field) structures. The following conditions have seen assumed : diffusion depth $0.2 \mu$; diffusion length of minority carriers $108 \mu$, acceptor concentration in the base material $N_{\mathrm{a}}=10^{16} \mathrm{~cm}^{-3}, \mathrm{AM} 1$ illumination [193].]

$\mathrm{NaOH}$ chaud. (AM1 signifie Air Mass 1 c'est-à-dire correspond au spectre solaire au niveau de la mer.)

\subsubsection{Accroissement du rendement de conversion.}

- Amélioration du rendement spectral en U.V. Le spectre solaire présente une densité relativement élevée de photons U.V. Or ces photons sont fortement absorbés dans le silicium très dopé formant la barrière de potentiel et n'ont de ce fait que très peu de chance de dépasser cette zone $\mathrm{N}^{+}$. Il faut donc réduire la profondeur de jonction ; celle-ci a passé progressivement de $1 \mu$ à $0,4-0,5$ puis récemment à $0,1 \mu$ pour les cellules dites violettes [18-19]. Notons que cette technologie entraîne quelques problèmes au niveau de la résistance superficielle qui est notablement accrue.

Remarquons que le rendement U.V. pourrait également être augmenté en incluant dans la fenêtre d'entrée d'encapsulation de la cellule un décaleur de longueur d'ondes absorbant les rayonnements U.V. et libérant des photons dans le visible. Mais le rendement pourra-t-il être assez élevé ?

- Amélioration de la collecte des porteurs. Dans une cellule normale la plus grande partie des porteurs photogénérés aura à diffuser vers la zone de charge d'espace avant de pouvoir participer au courant. En préparant les jonctions perpendiculairement à la surface la zone désertée pénétrera profondément dans le silicium réduisant la distance de diffusion des porteurs avant leur collecte. Quelques structures de ce type ont été réalisées [20-24] en creusant des petits fossés à la surface du silicium par attaque chimique et en effectuant une diffusion thermique d'impuretés limitées à ces fossés. Des rendements de conversion voisins de $15 \%$ (AM1) ont été atteints.
- Réduction de la réflexion. - Un accroissement du nombre de photons absorbés peut être atteint par l'emploi d'une structure superficielle texturisée [25] présentant une absorption totale pour la quasi-totalité des photons incidents, d'où leur nom de cellules noires (black cells). Cette surface est obtenue par attaque chimique préférentielle de cristaux convenablement orientés.

- Amélioration de la tension en circuit ouvert. Les tensions en circuit ouvert des cellules se sont progressivement améliorées, passant de 500 à $600 \mathrm{mV}$, par accroissement des dopages du matériau de base et de la zone superficielle. Des valeurs de $650 \mathrm{mV}$ sont (Fig. 9) théoriquement possibles pour des concentrations d'impuretés du matériau de base $P$ de $10^{17} \mathrm{~cm}^{-3}$ et un contrôle de la vitesse de recombinaison en surface. Toutefois, une partie du gain escompté peut être perdue par suite de la réduction à la fois des longueurs de diffusion et de la largeur de bande interdite (forts dopages).

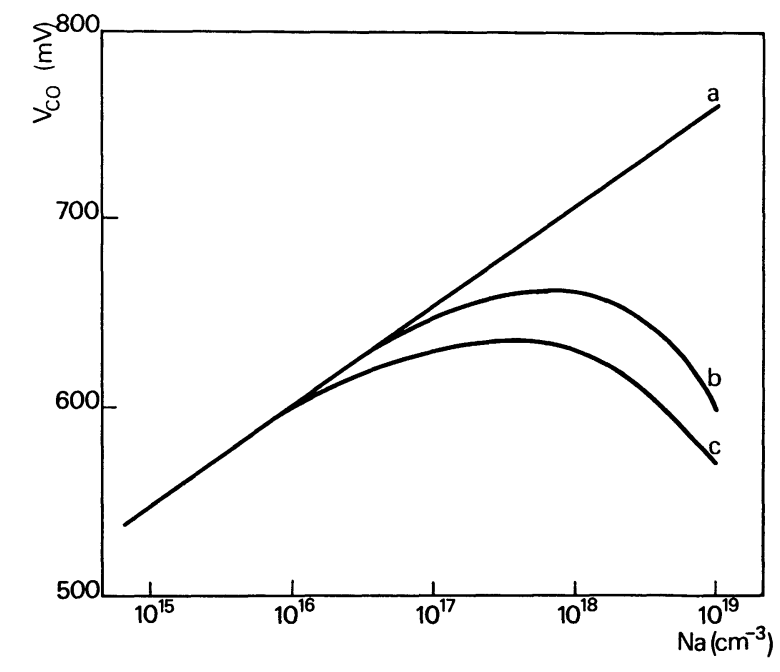

Fig. 9. - Tension en circuit ouvert de la photopile en fonction de la concentration en impuretés de la couche $\mathrm{P}$ de base : $a$ ) théorie simplifiée, $b$ ) d'après [194], $c$ ) d'après [195].

[Open circuit voltage as a function of doping level of the P-type base material by assuming a simplified theory $a$ ) and two more realistic conditions described in ref. [194] for curve $b$ ) and [195] for curve $c$ ).]

On pense généralement que la combinaison de plusieurs de ces méthodes permettra un gain de conversion de 3 à $4 \%$, qui passerait de 12-13 à 16$17 \%$. Il convient de noter qu'il est possible dès à présent de préparer au laboratoire des cellules ayant ce rendement, mais ces technologies seront-elles économiquement industrialisables?

La filière monocristalline est donc loin d'être épuisée. Il est probable que dans les cinq années à venir elle constituera toujours la voie industrielle prédominante. Dès à présent, le prix du Watt crête sur le marché international est voisin de $50 \mathrm{~F}$ [26]. 
2. Nouvelles méthodes de préparation de silicium monocristallin en couches minces. - Bien avant le développement des cellules solaires terrestres on avait tenté de préparer directement des monocristaux de germanium et de silicium en couches minces à partir d'un bain fondu, afin de supprimer l'usinage des matériaux. Dans le problème qui nous intéresse ici, il faudra se souvenir que seule la surface horaire des plaquettes produite et son coût seront d'importance. Une étude comparative [28] massif-couches minces, montre qu'il faut tirer plusieurs rubans à la fois à des vitesses élevées pour atteindre des surfaces horaires équivalentes à celles des monocristaux massifs découpés en tranches (Fig. 10). On a proposé dans la littérature de nombreuses méthodes de préparation de ces films, nous nous limiterons à quelques approches récentes.

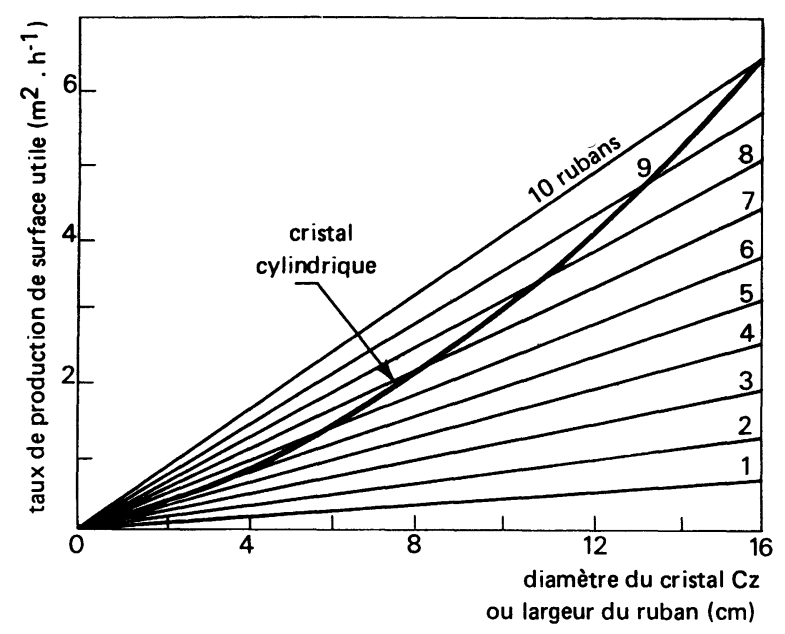

Fig. 10. - Taux de production de surfaces unitaires de matériaux à partir de monocristaux massifs découpés en tranches d'épaisseur $500 \mu$ ou de rubans [27].

[Unit area production rate as a function of single crystal diameter after slicing in $500 \mu$ wafers or by direct sheet growth [27].]

2.1 Croissance D'Un Film par LA MÉthode DE CZOCHRALSKI EN PRÉSENCE D'UN CONTOUR (edge defined film growth, E.F.G.) proposé par MobilTyco [28-35]. - Dans son principe, cette méthode est simple et économique : on plonge deux plaques rectangulaires séparées de quelques centaines de microns dans un bain de silicium fondu (Fig. 11). Par capillarité le silicium pourra monter entre les deux plaques jusqu'à leur limite supérieure où il sera mis en contact d'un germe monocristallin. Si ce dernier est animé d'un mouvement de déplacement vertical il va entraîner le silicium qui va se solidifier en un ruban ayant la forme donnée par le contour. Celui-ci pourra être enroulé sur une grande bobine ou découpé directement.

On comprendra aisément que le capillaire, porté à plus de $1400^{\circ} \mathrm{C}$, constitue le point crucial dans cette technologie (Fig. 12). Le graphite semble

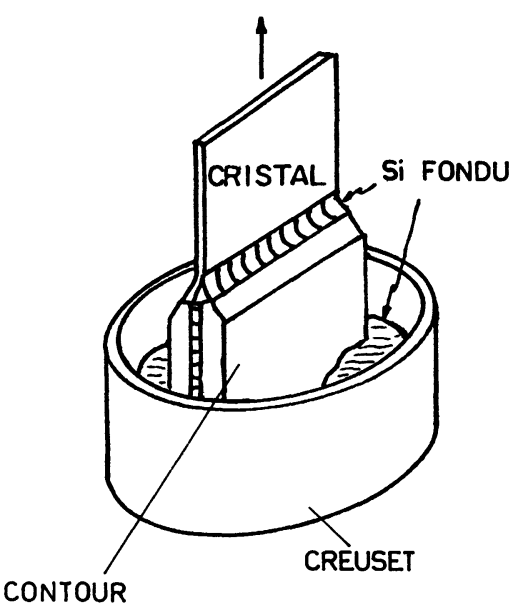

Fig. 11. - Tirage d'un ruban de silicium à partir d'un film délimité par un contour EFG (28-35) (TYCO).

[Edge defined silicon ribbon growth (EFG) [28-35].]

conduire actuellement aux meilleurs résultats. La méthode a été optimalisée sur des installations tirant un seul ruban de largeur $25 \mathrm{~mm}$, d'épaisseur $250 \mu$ à une vitesse de $25 \mathrm{~mm} / \mathrm{min}$. La vitesse maximale de tirage dépend essentiellement de l'épaisseur du ruban. Des progrès très importants ont été faits récemment puisque des films de $7,5 \mathrm{~cm}$ de largeur ont été préparés en continu à une vitesse de $7,5 \mathrm{~cm} / \mathrm{min}$. Pour évacuer la chaleur de fusion importante qui se dégage, tout en maintenant le gradient thermique voulu il est nécessaire d'avoir un refroidissement par eau et gaz inerte convenablement étudié. En effet, à l'interface liquide solide on passe très rapidement de plus de $1400{ }^{\circ} \mathrm{C}$ à $1200^{\circ} \mathrm{C}$. Pour atténuer les tensions internes résultant de ce choc thermique un four de recuit à $1100^{\circ} \mathrm{C}$ est inclus dans l'enceinte. Le cœur de ces

ROLE DU CONTOUR

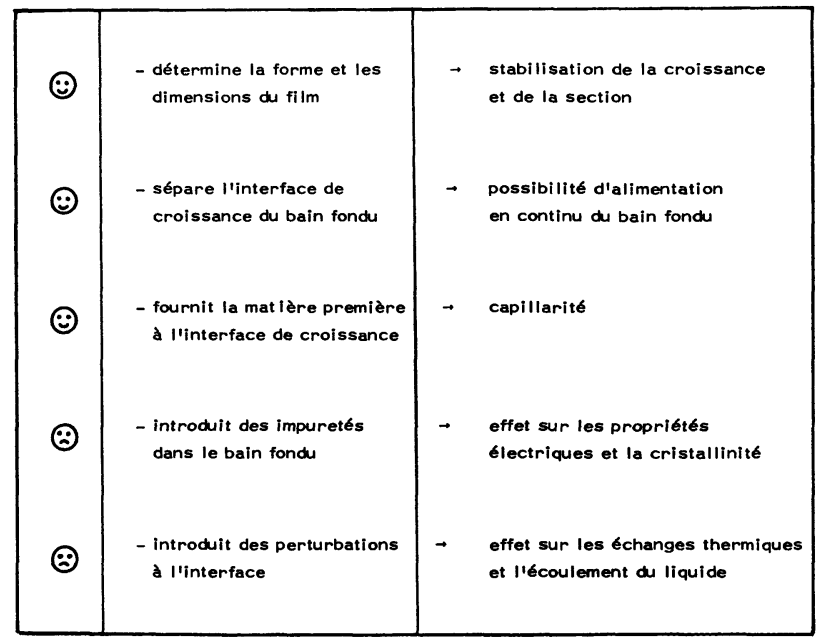

Fig. 12. - Rôle du contour dans la croissance EFG.

[Role of the die in EFG ribbon growth.] 
appareils est formé d'un module compact (Fig. 13) plongeant dans le bain, facilement interchangeable. La juxtaposition de plusieurs modules permet de tirer plusieurs films à la fois dans une même installation. Une association de 5 modules tirant des rubans de grande largeur vient d'être réalisée. L'approvisionnement en matière première se fait en continu à partir d'un cyclindre de silicium poussé progressivement dans le bain de façon à maintenir constant le niveau du liquide.

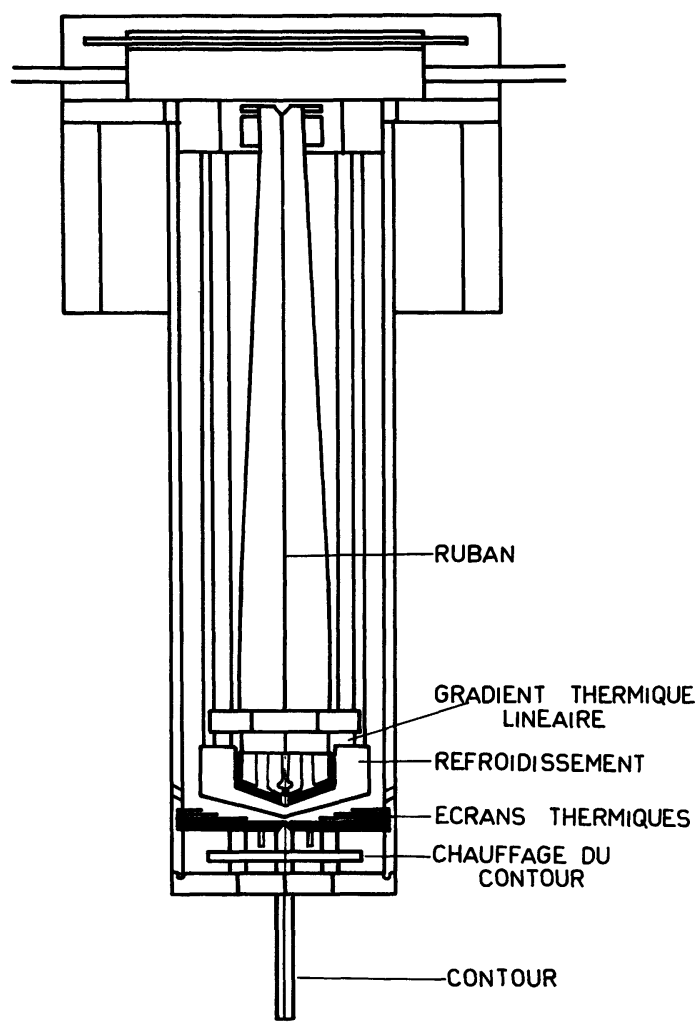

Fig. 13. - Schéma de principe d'une installation de tirage de silicium en ruban devant faire partie d'une machine tirant plusieurs rubans simultanément.

[Schematic of an EFG ribbon growth unit entering in a multiple sheet growth apparatus.]

Le rapport surface sur volume élevé, les gradients thermiques importants, le contact du matériau avec les parois du capillaire ont posé de nombreux problèmes de cristallinité et de contamination superficielle. En effet, les longueurs de diffusion des porteurs dans les premiers cristaux variaient très notablement d'un point à l'autre d'un même cristal, ce qui se traduisait par des écarts importants de performances des cellules. Il semble que ce point ait été très notablement amélioré récemment puisque des cellules de rendement supérieur à $10 \%$ peuvent être préparées avec un taux de réussite important.

Une estimation de coûts suivant différents scénari vient d'être effectuée : en 1978 une installation tirant 5 rubans de largeur $50 \mathrm{~mm}$ à une vitesse de
$50 \mathrm{~mm} / \mathrm{min}$. pendant 52 cycles annuels de durée 116 heures produirait environ $2000 \mathrm{~m}^{2} /$ an de plaquettes de base pour cellules solaires au prix de $800 \mathrm{~F} / \mathrm{m}^{2}$. Vers 1985 ce prix tombera à moins de $100 \mathrm{~F} / \mathrm{m}^{2}$ en supposant qu'un seul opérateur fera fonctionner deux installations à 5 modules chacune, tirant des rubans de $7,5 \mathrm{~cm}$ de largeur à raison de $7,5 \mathrm{~cm} / \mathrm{min}$., pour un temps actif de $67 \%$ et un rendement de conversion du polycristal $(50-100 \mathrm{~F} / \mathrm{kg})$ en ruban de $75 \%$. Notons que ce prix est inférieur au plafond fixé par l'administration ERDA américaine pour 1985 !

Cette approche semble donc ouvrir des perspectives très prometteuses; d'autres laboratoires importants, tel IBM se consacrent également à cette filière.

Une variante de cette méthode a été proposée récemment en France par Ugine-Kuhlmann ainsi que par RCA aux Etats-Unis. Son principe (Fig. 14) est proche de celui proposé par Stepanov : le silicium est fondu dans un creuset en graphite muni à sa partie inférieure d'une ouverture capillaire de forme convenable. Si on place un germe à l'extrémité inférieure de la goutte et que l'on établit à ce niveau un gradient de température convenable, on peut tirer un cristal vers le bas, à condition d'alimenter le capillaire en silicium liquide (36).

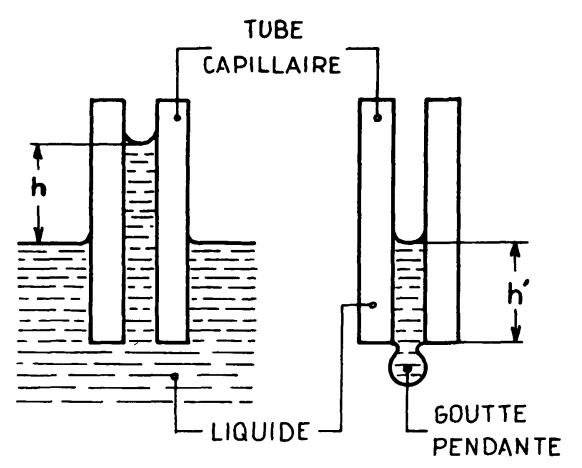

PRINCIPE DE LA GOUTTE PENDANTE

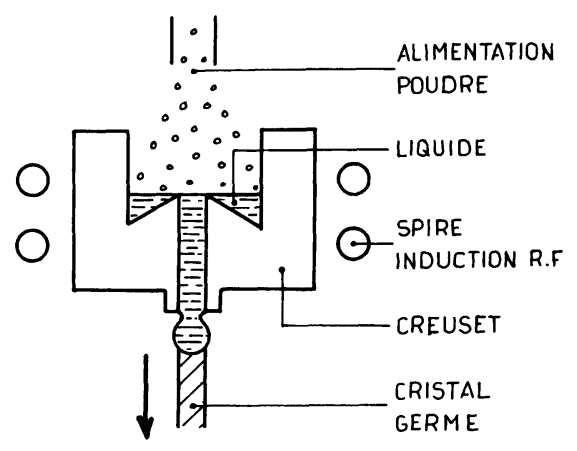

SCHEMA GENERAL DU CREUSET (VUE EN COUPE)

Fig. 14. - Principe du tirage de silicium par la goutte pendante (Ugine-Kuhlmann).

[Principle of sheet growth by a pendant drop process [36].] 
2.2 Cristallisation D'Un RUban a partiR D'Un FILM POLYCRISTALLIN (" ribbon to ribbon growth "). $\mathrm{Au}$ lieu de tirer directement des films monocristallins à partir d'un bain fondu comme ci-dessus, Motorola (37) a proposé de former d'abord des rubans polycristallins par un procédé EFG simplifié, puis de fondre une mince zone de ce ruban au moyen d'un faisceau laser de puissance balayant les deux faces (Fig. 15) pour produire la cristallisation.

Ceci constitue une première application des faisceaux laser dans la technologie des semiconduc-
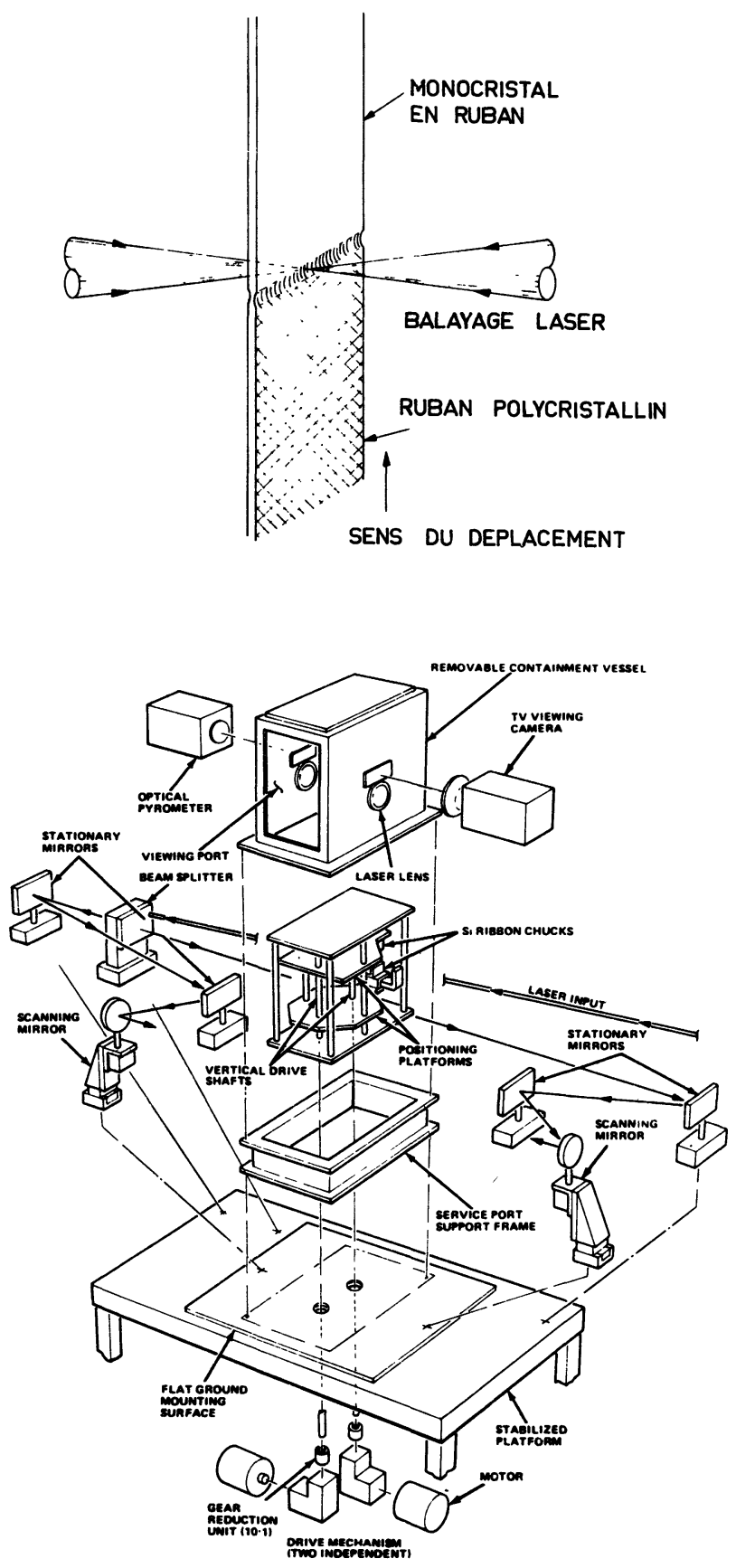

Fig. 15. - Recristallisation de silicium en ruban par faisceau laser, principe et réalisation [37] (MOTOROLA).

[Ribbon to ribbon process for growing single crystals from polycristalline feedstock. Exploded view of the apparatus.] teurs, nous verrons par la suite que d'autres possibilités existent.

Des rubans de $25 \mathrm{~mm}$ de large ont ainsi été obtenus à une vitesse de $50 \mathrm{~mm} / \mathrm{min}$. Les rendements des premières cellules approchent $8 \%$. Des problèmes de monocristallisation restent à résoudre avant de pouvoir atteindre les objectifs fixés : rubans de $7,5 \mathrm{~cm}$ de large, tirés à $15 \mathrm{~cm} / \mathrm{min}$., cellules de rendement $10 \%$.

2.3 Croissance DendritiQue. - Westinghouse avait proposé dès 1959 une méthode de croissance dendritique de germanium et de silicium. Toutefois, des problèmes de monocristallisation et de fortes densités de dislocations n'avaient pu être résolus à cette époque de sorte que la qualité requise de matériau applicable directement aux dispositifs semiconducteurs ne fut pas atteinte.

Une approche nouvelle du problème a permis d'accomplir des progrès notables. Deux dendrites sont disposés verticalement et parallèlement, distantes l'une de l'autre de $2-3 \mathrm{~cm}$, l'ensemble servant de germe de croissance. A l'interface liquide-solide un film continu de silicium se forme maintenu par les deux dendrites. Des rendements de conversion intéressants ont été atteints $\left(V_{\mathrm{oc}}=0,55, J=35 \mathrm{~mA} / \mathrm{cm}^{2}\right.$, $F F=0,75)$. Une production en continu est possible au moyen d'un appareillage schématisé sur la figure 16 [38-42].
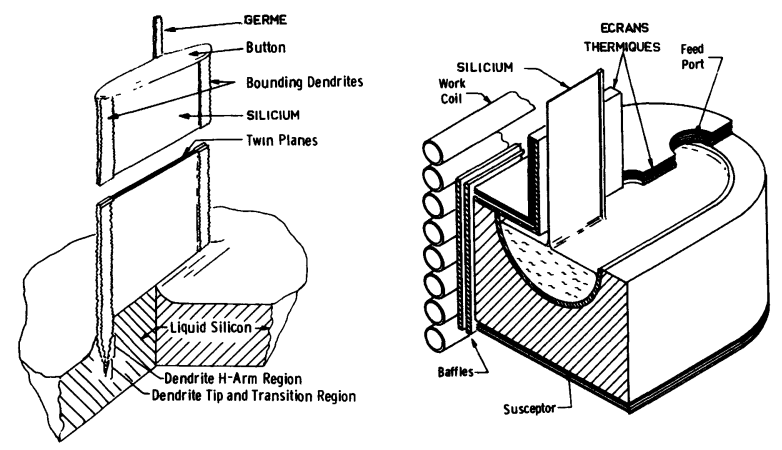

Fig. 16. - Représentations schématiques du tirage de silicium web [42] (Westinghouse).

[Schematic section of dendritic web growth.]

2.4 Croissance ÉPITAXIAle EN PHASE SOldDE (« SPE»). - On avait observé il y a quelques années [43-48] qu'il était possible de faire migrer sélectivement, dans une structure métal-semiconducteur chauffée, soit le métal vers le semiconducteur soit le contraire, suivant la nature du métal. Ce déplacement se fait bien en dessous des températures de formation d'alliages.

Plus récemment, des réactions en phase solide [49-54] ont été employées pour faire croître des couches épitaxiales de silicium et de germanium sur un substrat de même nature mais cristallin à partir d'une couche amorphe déposée par-dessus le métal 
par migration à travers cette couche métallique dont la nature est convenablement choisie. L'aluminium et le palladium ont été les plus employés à ce jour pour former respectivement des films monocristallins de silicium ou des siliciures [55].

La force de déplacement dans ce procédé résulte de l'énergie libre plus élevée dans le semiconducteur amorphe que dans le cristal. La présence d'oxygène semble réduire considérablement la possibilité de migration, de plus des reliquats d'aluminium subsistent après la recristallisation épitaxiale. Il est donc trop tôt pour connaître les possibilités réelles de cette méthode.

3. Silicium polycristallin. - 3.1 GÉNÉRALITÉs. Le terme polycristallin est assez mal adapté au matériau non cristallin pour cellules solaires, car il désigne un amas de cristaux dont les dimensions et les orientations sont très variables, séparés par des zones perturbées, les joints de grains [56-57]. En effet, parmi ces cristaux orientés au hasard, seuls ceux placés directement sous le contact redresseur et exposés au flux solaire participent à la collecte des porteurs, les autres sont isolés par la barrière de potentiel apparaissant aux joints de grains (Fig. 17). Si par contre, tous les cristaux sont disposés perpendiculairement à la surface de la barrière de potentiel et si leurs dimensions individuelles sont suffisantes pour s'étendre jusqu'au contact ohmique, on peut considérer l'ensemble comme une juxtaposition de cellules cristallines avec certains effets de bords, de sorte que le rendement de conversion pourra être

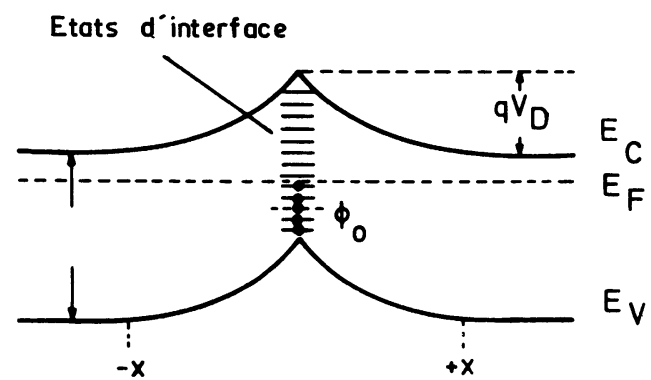

a) dans l'obscurité

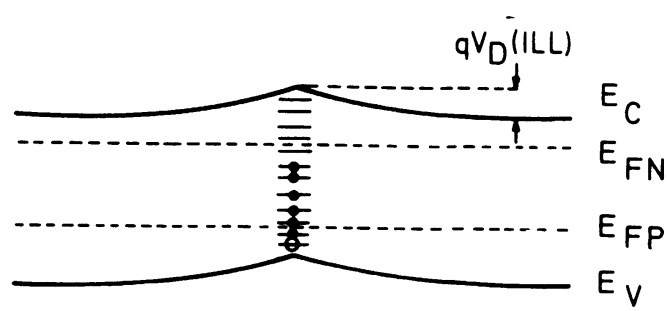

b) sous éclairement

Fig. 17a. - Diagramme de bandes au voisinage d'un joint entre deux grains. $X$ représente la largeur de la zone de charge d'espace [196].

[Energy band diagram of a region surrounding a grain boundary in dark and under illumination.]

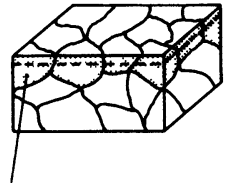

GRAINS UTILES

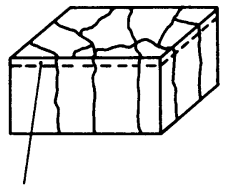

JONCTION

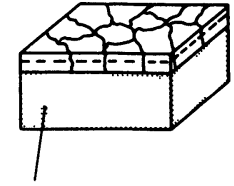

SUBSTRAT
Fig. 17b. - Différentes structures de silicium polycristallin massif ou en couches minces [81].

[Various structures of polycristalline cells. Only the crystals extending from the front to the back contact contribute to the charge collection.]

proche de celui d'un monocristal. Cette structure de grains est recherchée par les divers groupes qui étudient les matériaux polycristallins pour piles solaires. On désignera ce type de silicium de non cristallin ou semicristallin plutôt que de polycristallin.

Plusieurs auteurs [56-59] ont calculé les performances de telles cellules en tenant compte à la fois

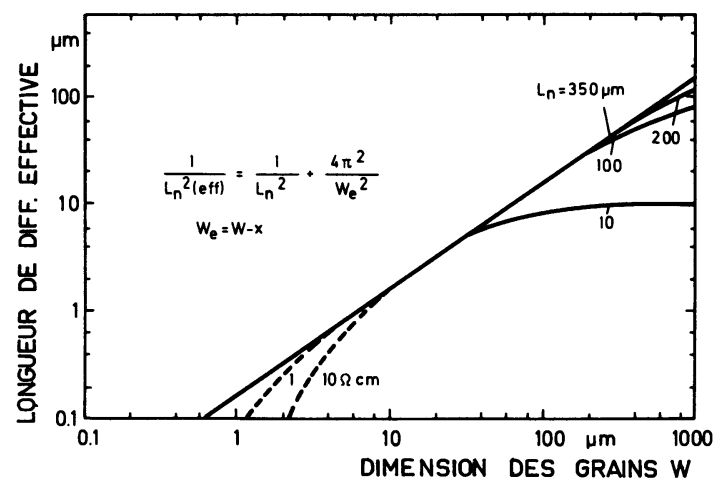

Fig. 18a. - Longueur de diffusion effective des porteurs minoritaires en fonction des dimensions des polycristaux pour différentes valeurs des longueurs de diffusion à l'intérieur de ces polycristaux [81].

[Effective minority carrier diffusion length as a function of polycristalline grain size for various values of bulk diffusion length [81].]

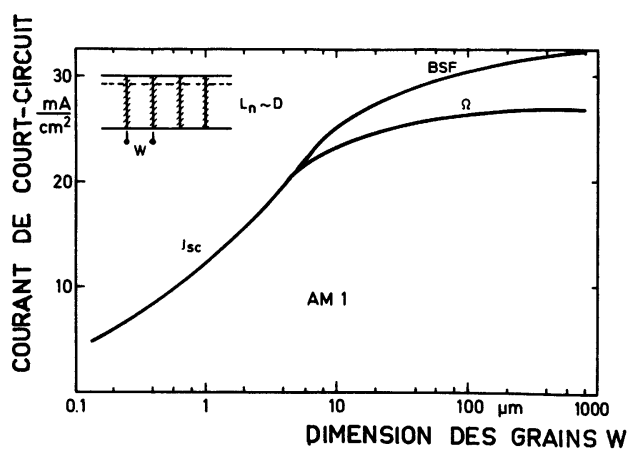

Fig. 18b. - Courant de court-circuit sous éclairement AM1 en fonction des dimensions des polycristaux avec (BSF) ou $(\Omega)$ champ arrière (back surface field) [81].

[Short circuit current density versus grain size calculated for a $0.3 \mu$ deep $\mathrm{N}^{+} / \mathrm{P}$ junction and AM1 illumination without $(\Omega)$ and with (BSF) back surface field.] 


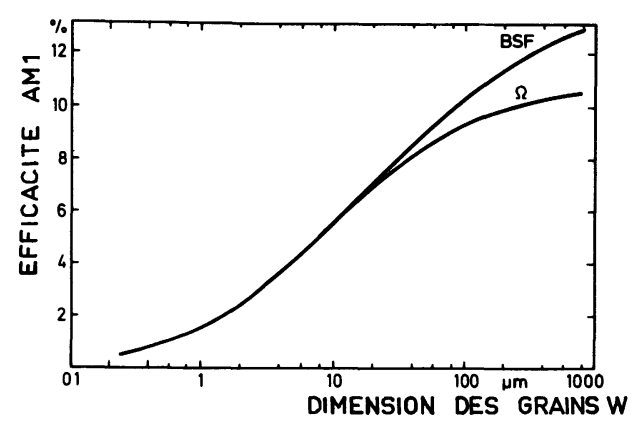

Fig. 18c. - Rendement de conversion photovoltaïque sous éclairement AM1 en fonction des dimensions des polycristaux [81].

[Conversion efficiency calculated under the same conditions as above as a function of grain size.]

des effets de volume de chaque cristal individuel et des effets de bord de ce matériau fibreux. On a ainsi introduit la longueur de diffusion effective des porteurs dont la valeur dépend des propriétés de chaque cristal et de ses dimensions (Fig. 18). Lorsque ces dernières sont supérieures aux longueurs de diffusion effectives des porteurs, on atteindra une collecte proche de celle existant dans le monocristal de même qualité, de sorte que les rendements de conversion ne seront pas notablement différents.

Le tableau (Fig. 19) résume les différentes étapes dans l'élaboration des substrats polycristallins. En fait, de nombreuses approches sont possibles, nous les avons regroupées ci-dessous en trois groupes :

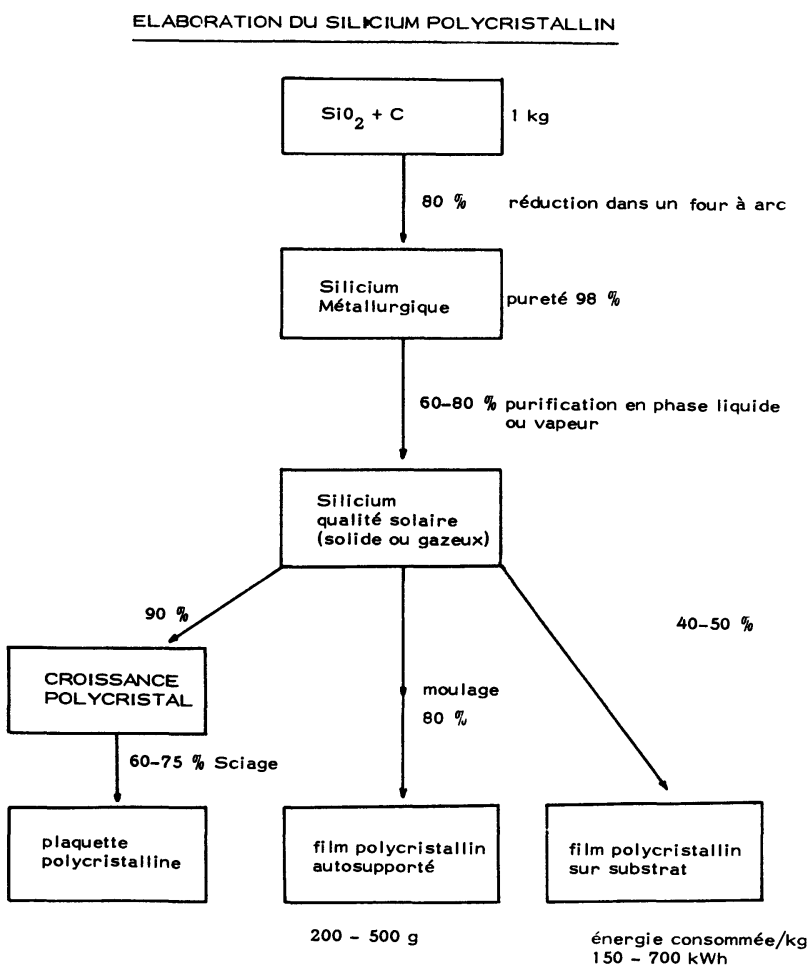

Fig. 19. - Principales étapes dans l'élaboration du silicium polycristallin.

Processes for the production of solar grade polycristalline silicon sheets.]
3.1.1 Polycristaux Czochralski massifs [60-61]. Nous avons vu plus haut qu'il peut être avantageux de tirer des polycristaux de silicium si le matériau de départ contient de fortes concentrations d'impuretés. En partant de germes polycristallins des grains de surfaces $1 \mathrm{~mm}^{2}$ à $1 \mathrm{~cm}^{2}$ peuvent être obtenus et des rendements de conversion de l'ordre de $9 \%$ ont été publiés [61]. En fait, l'ensemble des problèmes sont très voisins de ceux rencontrés précédemment pour les monocristaux (sciage...).

3.1.2 Films minces sur substrat. - Pour n'employer que la quantité de silicium nécessaire à l'absorption notable $(50-100 \mu)$ du spectre solaire et pour supprimer les traitements d'usinage il est intéressant de déposer ces films directement sur des substrats bon marché. De nombreuses méthodes sont étudiées, elles peuvent être classées en trois catégories :

- Dépôt en phase vapeur de silicium par évaporation thermique ou par réaction chimique en phase vapeur (CVD); quelques techniques expérimentales et les résultats obtenus sont reportés sur le tableau de la figure 20.

- Dépôt par un solvant : il est possible de déposer des couches de silicium par épitaxie en phase liquide vers $500{ }^{\circ} \mathrm{C}$ [71-72]. Divers solvants ont été employés, notamment un alliage étain (80\%)-plomb (20\%) et gallium-aluminium. Toutefois, les rendements de conversion de cellules préparées sur des substrats de silicium ou d'aluminium sont encore faibles.

- Dépôt dans un bain de silicium fondu. - La première cellule de ce type fut certainement celle réalisée au LEP en 1960 par simple chauffage dans une nacelle en graphite de poudre de silicium recouverte d'une couche de pyrocarbone. La couche polycristalline d'épaisseur $1 \mathrm{~mm}$ était ensuite soumise à une diffusion de phosphore pour réaliser la jonction, le rendement de conversion pouvait atteindre $6 \%$ [73].

Les mêmes auteurs ont imaginé récemment [74-77] une méthode de dépôt de silicium polycristallin sur un ruban de carbone défilant dans la zone fondue, dont le principe est représenté sur la figure 21 : un lingot de silicium polycristallin de section carrée est fondu à sa partie supérieure à l'aide d'un enroulement H. F. Un substrat en forme de ruban est disposé en regard de chacune des deux faces opposées du lingot. La zone fondue de silicium est mise en contact avec les rubans et les mouille; ceux-ci sont alors tirés vers le haut entraînant un film liquide qui cristallise à travers un gradient thermique convenable. Les grains sont orientés dans la direction de croissance, ils présentent une largeur de 100-300 $\mu$. Des homo-, hétéro-jonctions ainsi que des structures M-I-S ont permis d'atteindre des rendements de conversion de plus de $6 \%$; les longueurs de diffusion s'accroissent sous fort éclairement par suite de la saturation de certains pièges [78]. Des problèmes de pollution par le carbone restent à résoudre, de même que l'opti- 
DEPOT DE SILICIUM SUR SUBSTRAT (PAR PHASE VAPEUR)

\begin{tabular}{|c|c|c|c|c|c|}
\hline DEPOT PAR & NATURE DU SUBSTRAT & $\begin{array}{l}\text { CONDITIONS } \\
\text { EXPERIMENTALES }\end{array}$ & $\begin{array}{l}\text { DIMENSIONS GRAINS- } \\
\text { ORIENTATION }\end{array}$ & $\begin{array}{l}\text { RENDEMENT } \\
\text { CONVERSION }\end{array}$ & REF. \\
\hline EVAPORATION & $\begin{array}{l}\text { aluminium } \\
\text { alliage acier }\left(600^{\circ}\right) \\
\text { saphire }\left(1000^{\circ} \mathrm{C}\right)\end{array}$ & $\begin{array}{l}\text { évaporation canon à e } \\
10 \mu \text { épaisseur } \\
\text { canon } \mathrm{e}^{-} 83 \mu\end{array}$ & $\begin{array}{l}4 \mu \text { perp. surface } \\
5 \mu\end{array}$ & $\begin{array}{l}4 \% \\
1-2 \%\end{array}$ & $\begin{array}{l}{[62]} \\
{[63]} \\
{[64]}\end{array}$ \\
\hline $\begin{array}{l}\text { REACTION } \\
\text { CHIMIQUE } \\
\text { PHASE VAPEUR } \\
\text { (CVD) }\end{array}$ & $\begin{array}{l}\text { acier }\left(900-1150^{\circ}\right) \\
+ \text { verre borosilicaté } \\
\text { graphite }\left(1250^{\circ} \mathrm{C}\right) \\
\text { silicium métallurgique } \\
\text { graphite + silicium } \\
\text { métallurgique purifié } \\
\text { et recristallisé }\left(1100^{\circ} \mathrm{C}\right) \\
\text { étain fondu sur } \\
\text { acier (1000 } \mathrm{C}) \\
\text { étain fondu sur } \\
\text { graphite } \\
\text { étain fondu } \\
\text { silicium métallurgique } \\
\text { (grains } \mathrm{mm})\end{array}$ & $\begin{array}{l}\text { décomposition du } \\
\text { silane } \\
\text { réduction pyrolitique } \\
\text { de trichlorosilane } \\
0,4 \mu / m i n . \\
\text { réduction thermique } \\
\text { de trichlorosilane } \\
1 \mu / m i n ., 20-30_{\mu} \\
\text { décomposition de } \\
\text { silane } \\
\text { épaisseur } \mathrm{Sn}: \\
5-10 \mu \\
\text { décomposition de } \\
\text { silane } \\
\text { réduction de } \mathrm{SiH}_{2} \mathrm{Cl}_{2} \\
\text { par } \mathrm{H}_{2} \\
25 \mu\end{array}$ & $\begin{array}{l}30-40 \mu \\
100 \mu\end{array}$ & $\begin{array}{c}0,5 \% \\
4 \% \\
6 \% \\
\left(0,53 V^{2}, 15\right. \\
\mathrm{mA} / \mathrm{cm}^{2}, F F= \\
\left.0,71,20 \mathrm{~cm}^{2}\right)\end{array}$ & $\begin{array}{l}{[65]} \\
{[68]} \\
{[68]} \\
{[68]} \\
{[66]} \\
{[67]} \\
{[69-70}\end{array}$ \\
\hline
\end{tabular}

Fig. 20. - Principaux résultats obtenus pour des cellules solaires préparées à partir de silicium déposé en phase vapeur sur divers substrats.

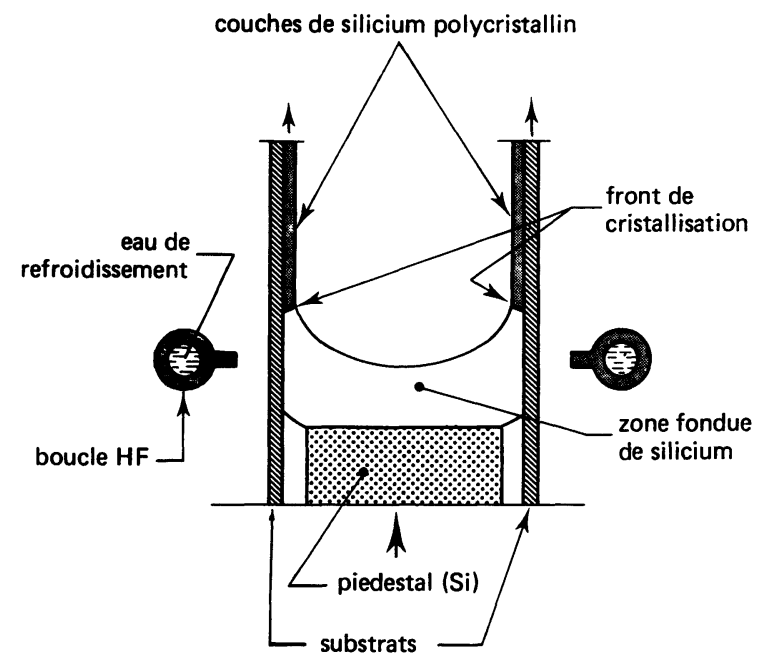

Fig. 21. - Schéma de principe du dépôt de silicium polycristallin sur bande de graphite par léchage [75].

[Conceptual design of the ribbon against drop pulling process. Detail of the solid-liquid interface on the graphite sheet [75].]

malisation des épaisseurs de films et les vitesses de tirage (le carbure de silicium peut être formé).

Le LEP [6] ainsi que Honeywell [79] ont proposé de déposer le silicium par simple trempage de graphite, ou d'une céramique dans un bain fondu. Aucun résultat de cellule préparée sur ces substrats n'est disponible actuellement (Figs. 22a et $b$ ).
[Main results obtained on cells prepared on vapour deposited silicon sheets on various substrates.]

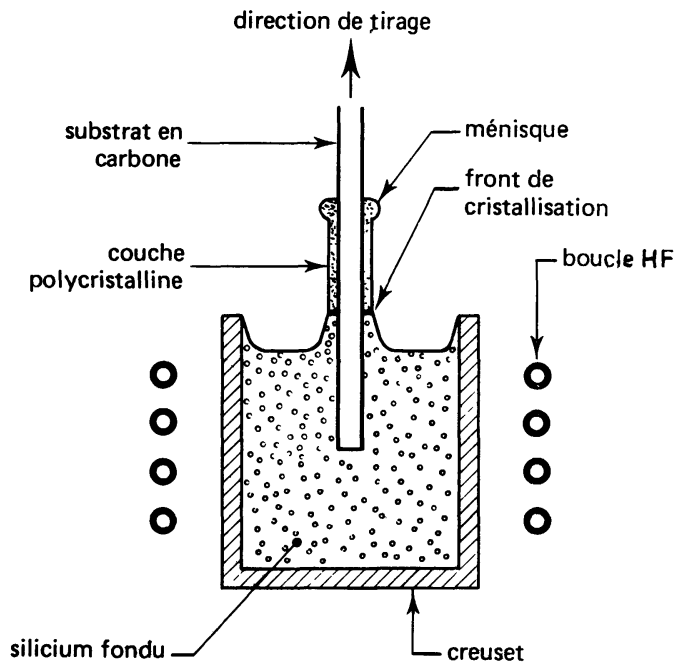

Fig. 22a. - Schéma de principe du dépôt de silicium polycristallin sur bande de graphite par trempage [6].

[Silicon deposition on graphite procedure by diping in molten silicon [6].]

3.1.3 Moulage de silicium. - Wacker a développé un procédé de fabrication de blocs plats de silicium polycristallin de structure fibreuse, qui consiste à verser le silicium fondu dans un moule en graphite présentant deux grandes faces planes et parallèles, l'une étant à $1200^{\circ} \mathrm{C}$ environ et l'autre à 500-600 ${ }^{\circ} \mathrm{C}$. 

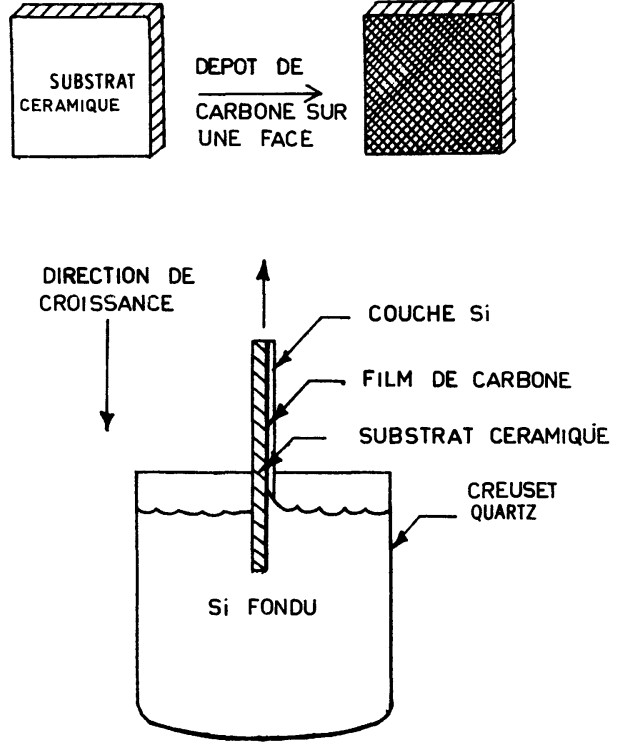

Fig. 22b. - Schéma de principe du dépôt de silicium polycristallin sur céramique par trempage (Honeywell).

[Silicon deposition on ceramic covered by a carbon film by diping [79].]

La solidification se fait en grains de dimensions $100 \mu$ à plusieurs millimètres orientés dans le sens du gradient thermique. Après refroidissement lent, les plaques sont démoulées et découpées en tranches [80]. Plus récemment, des plaquettes ont directement été préparées.

Les premières cellules réalisées à partir de ce type de matériau [81-82] ont permis de montrer que les joints de grains ne jouaient qu'un rôle secondaire et que des taux d'impuretés relativement importants pouvaient être tolérés. Des rendements de conversion pouvant atteindre $12 \%$ ont été publiés récemment (AM0) et des cellules de plus de $100 \mathrm{~cm}^{2}$ ont été réalisées [83].

Les premières feuilles minces préparées directement ont permis d'atteindre $6 \%$ de rendement.

4. Silicium amorphe. - Une réunion venant de se tenir aux Houches sur ce sujet, nous n'indiquerons ici que quelques généralités sur ce nouveau type de matériau solaire dont l'impact réel ne peut encore être apprécié à l'heure actuelle.

Jusque vers 1955 on crut que les matériaux amorphes ne pouvaient être des semiconducteurs, lorsque plusieurs théoriciens et expérimentateurs prouvèrent le contraire. Toutefois, l'existence d'un grand nombre de liaisons non saturées dangling bonds conduisait à des densités d'états dans la bande interdite mobility gap $(1,4-1,6 \mathrm{eV})$ très importantes, empêchant tout dopage de ce matériau. Tout récemment, on a constaté [84-87] que la présence d'hydrogène réduisait considérablement les queues de bandes et que, par conséquent, un dopage du matériau devenait possible. La structure exacte de ce matériau contenant de $10-30 \%$ d'hydrogène est encore mal établie actuellement : certains auteurs parlent de polymères $\mathrm{SiH}_{x}$, d'autres de semiconducteur de type I-IV.

4.1 Préparation du matériau. - Dépôt par décomposition de silane $\mathrm{SiH}_{4}$ dans un champ H.F. sur des substrats d'acier ou de verre. L'adjonction de gaz contenant les dopants permet de préparer directement la structure n-p ou n-i-p (Fig. 23a) [88-92];

- dépôt par pulvérisation cathodique de silicium pur ou dopé sous atmosphère d'un gaz neutre en présence d'hydrogène (Fig. 23b) [93].

4.2 Performances des Cellules. - Les rendements de conversion théoriques, de l'ordre de $15 \%$ (88)-10\% (94) joints aux épaisseurs de silicium très faibles $(1-2 \mu)$ nécessaires pour absorber le spectre solaire rendent ce matériau très intéressant de sorte que de nombreux groupes s'y intéressent. Pour atténuer quelque peu cet enthousiasme, mentionnons que les meilleurs rendements expérimentaux ne dépassent pas 5,5\% [89] et qu'ils ne se sont pas améliorés au courant de l'année écoulée (du moins dans la littérature !). Un travail de recherche de longue haleine est maintenant nécessaire, après ces premiers résultats prometteurs.

Les structures sont de type homojonction (par dopage en cours de croissance, ou par implantation ionique), n-i-p, ou Schottky. Les meilleurs résultats ont été atteints pour ces dernières $\left(V_{0 \mathrm{c}}=800 \mathrm{mV}\right.$, $\left.I=12 \mathrm{~mA} / \mathrm{cm}^{2}, S=2 \times 10^{-2} \mathrm{~cm}^{2}\right)$.

$S$ 'il est clairement établi maintenant que les cellules solaires industrielles sans concentration seront (pour longtemps) à base de silicium, élément très répandu à la surface du globe et non toxique, la filière choisie pour son élaboration ne semble pas encore définitivement établie. Il semble, toutefois, que les techniques de réalisation de films en continu s'imposeront à terme, en particulier trois approches paraissent intéressantes :

- tirage de films mono- ou polycristallins, soit de type EFG, soit sur un substrat, soit dendritique ;

- moulage du silicium;

- dépôt de silicium amorphe hydrogéneré ; en partant de silicium faiblement purifié. Les vitesses de préparation d'une surface unitaire et le comportement des impuretés résiduelles constitueront peut-être les paramètres décisifs.

5. Réalisation de la barrière de potentiel. - Les techniques conventionnelles de réalisation de la barrière de potentiel utilisent toutes la diffusion thermique d'impuretés de type opposé à celui du substrat. Cette procédure offre de nombreux avantages, parmi lesquels il convient de citer :

- son utilisation quasi générale dans la réalisation de tous les autres dispositifs semiconducteurs actifs ; 


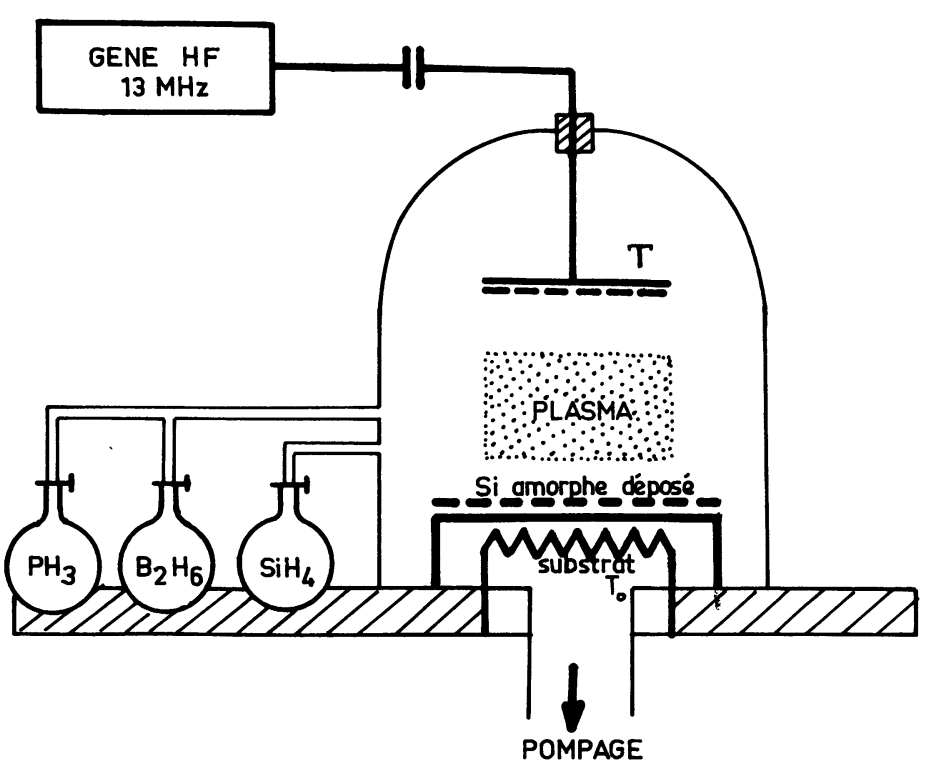

Fig. 23a. - Schéma de principe d'une installation de préparation de silicium amorphe par décomposition de silane $\mathrm{SiH}_{4}, a$ ) couplage HF inducif, $b$ ) capacitif.

[Schematic of an amorphous silicon preparation apparatus by silane decomposition by R.F., $a$ ) and capacity, $b$ ) coupling.]

Fig. 23b. - Schéma de principe d'une installation de préparation de silicium amorphe par pulvérisation cathodique sputtering.

[Schematic of an amorphous silicon preparation apparatus by sputtering.]

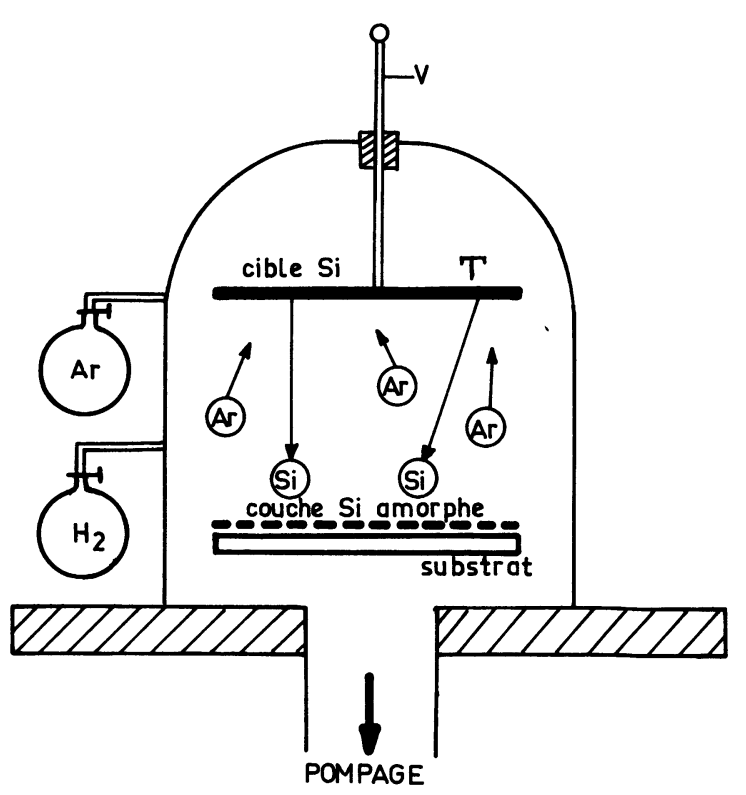

- sa facilité de mise en œuvre et la possibilité de traiter simultanément un grand nombre de plaquettes.

Elle offre également des inconvénients, surtout, pour les technologies futures :

- les nombreux masquages et traitements chimiques de surface;

- le chauffage à température élevée dégradant la durée de vie des porteurs;

- l'impossibilité d'opérer en continu, par défilement de films par exemple;
- un risque d'accumulation de dopants aux joints de grains mettent la diode en court-circuit. Toutefois, cet effet semble moins important que redouté il y a quelques temps. En effet, la recombinaison aux joints de grains peut être réduite par un dopage préférentiel préalable à la diffusion thermique proprement dite, de façon à obtenir la structure de la figure 24 , ce qui améliore même la collecte des porteurs générés loin des surfaces. Notons que des cellules obtenues par diffusion thermique sur des substrats polycristallins ont donné des rendements de $12 \%$. Mais d'autres 

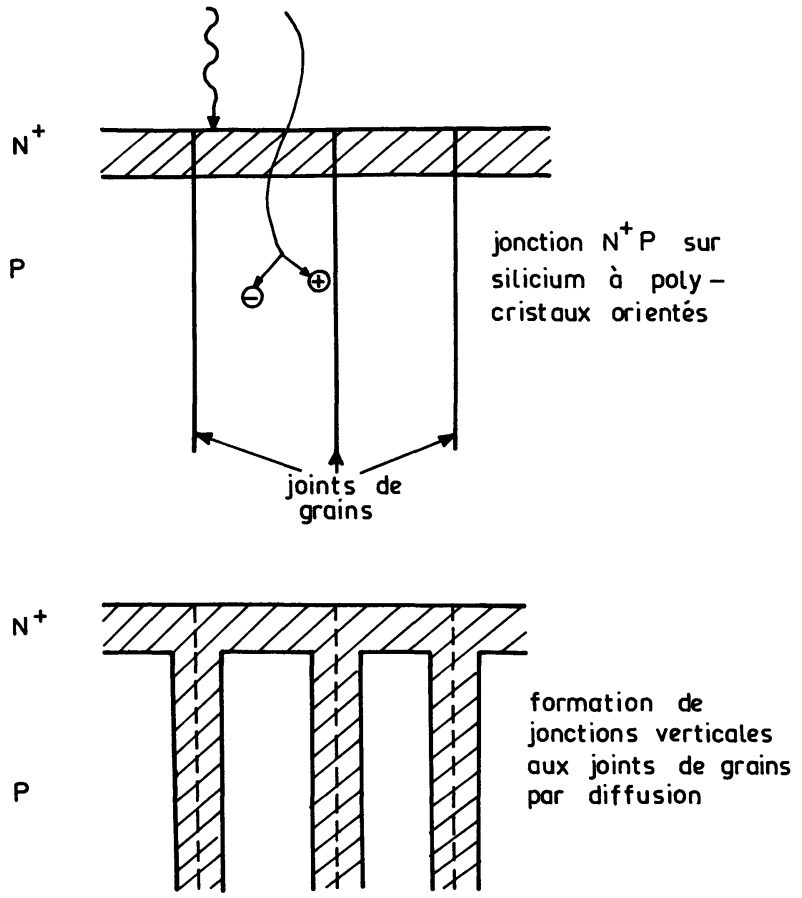

Fig. 24. - Schéma de cellules réalisées sur silicium polycristallin en l'absence (haut) et présence de jonctions collectrices aux joints de grains.

[Cross-section through a polycristalline (oriented) cell with grain boundaries. Possibility to prepare vertical junctions at these grain boundaries by diffusion, which will enhance the collection efficiency.]

alternatives existent pour la réalisation de la barrière de potentiel. Nous allons les considérer maintenant.

5.1 STRUCTURES MÉTAL-SEMICONDUCTEUR. - 5.1.1 Contact métal-semiconducteur. - $\mathrm{La}$ réalisation de la barrière de potentiel par dépôt d'un métal en couche mince sur un semiconducteur convenablement

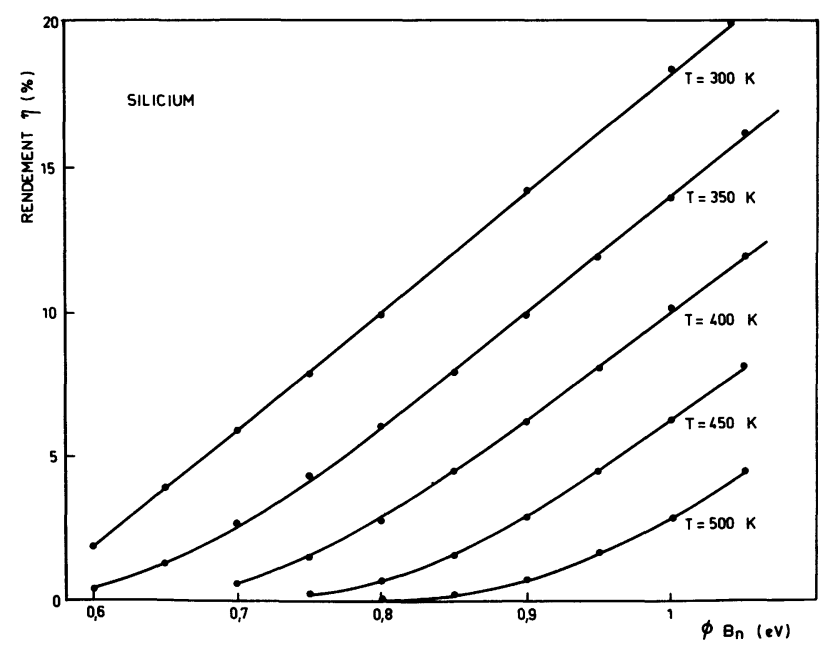

Fig. 25. - Variation du rendement de conversion en fonction de la hauteur de barrière des diodes Schottky à différentes températures.

[Evolution of the conversion efficiency of Schottky barriers as a function of barrier height and temperature.] traité (diode Schottky) présente des avantages séduisants : absence de tout traitement thermique, possibilité d'emploi de substrats polycristallins sans problèmes aux joints de grains, possibilité de mise en œuvre de grandes surfaces. Dans la pratique, toutefois, on a observé que les rendements de conversion sont faibles $(7-8 \%)$ par suite du courant d'obscurité trop élevé de ce dispositif à porteurs majoritaires. Comme le rendement de conversion croît rapidement avec la hauteur de la barrière de potentiel (Fig. 25) [95], on a cherché à augmenter celle-ci. Essentiellement quatre méthodes ont été envisagées :

- Choix du métal le mieux adapté : le meilleur sera celui qui présente le travail d'extraction le plus important dans le cas d'un substrat de type $\mathrm{N}$ et le plus faible pour le type $P$, si le modèle de Schottky est correct. En fait, il n'en est rien puisque les divers métaux (Fig. 26) conduisent à des hauteurs de barrière

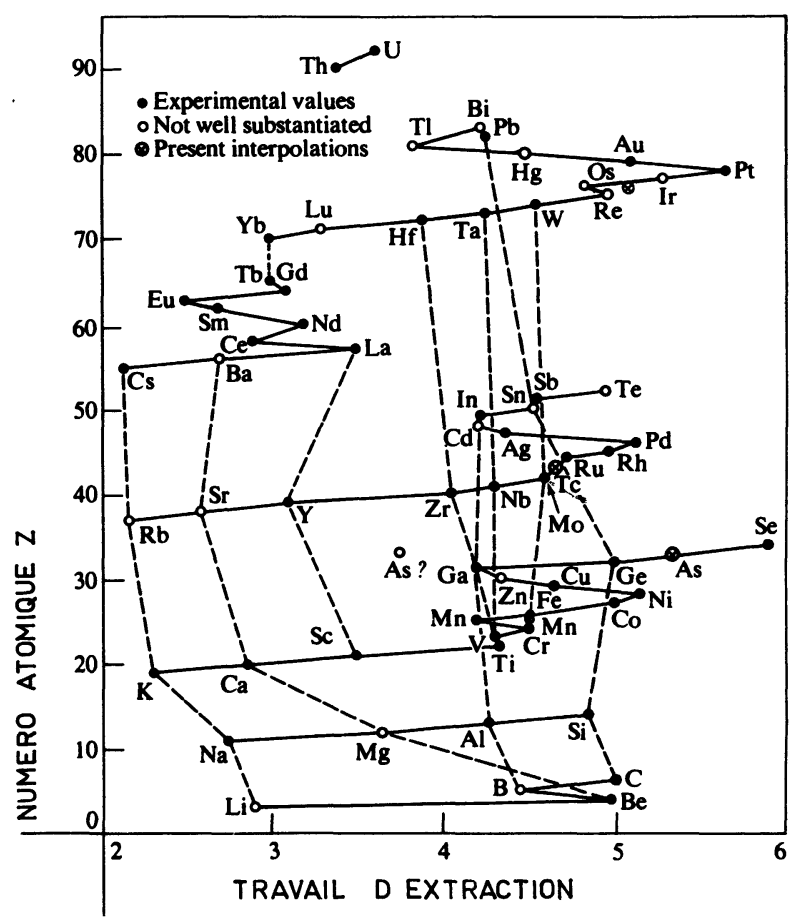

Fig. 26. - Travail de sortie de divers éléments de la table périodique.

[Work function of the various elements of the periodic table.]

(Fig. 27) limitées à $0,8 \mathrm{eV}$ environ. Les états de surface jouent un rôle important et l'oxygène est déterminant dans la hauteur de barrière qu'un métal peut donner [96]. En particulier, les phénomènes de "vieillissement" de ces structures sont dus à la migration de l'oxygène à travers la couche métallique et à son accumulation à l'interface métal-semiconducteur, où il neutralise les charges positives qui y sont accumulées après les traitements de décapage chimique [97-98].

Mentionnons également qu'une dégradation lente peut intervenir lorsque ces structures sont portées 


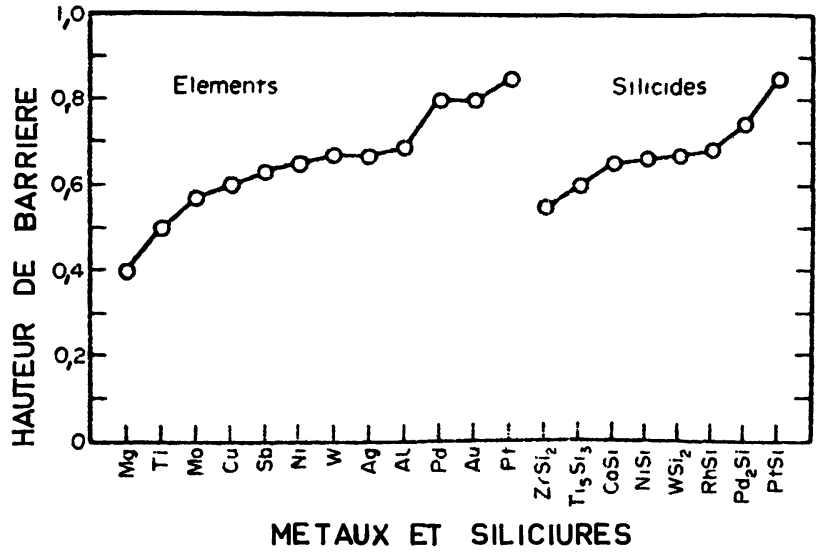

Fig. 27. - Hauteur de barrière de diodes Schottky et siliciures (valeurs exp.).

[Experimental values of barrier heights for various metals and silicides.]

à des températures dépassant $100^{\circ} \mathrm{C}$ par suite d'une migration du métal dans le semiconducteur ou de ce dernier vers le métal $[44,48]$.

- Recherche de films conducteurs de très forte électronégativité. Comme le travail d'extraction du métal croît avec l'électronégativité [99] il serait intéressant de disposer, pour des cristaux de type $\mathrm{N}$ des composés chimiques conducteurs à forte électronégativité. Des résultats prometteurs ont été publiés récemment [100-103] pour des semiconducteurs binaires, notamment avec des films de $\mathrm{SN}_{x}$ et $\mathrm{HgSe}$;

- Contrôle de la courbure des bandes dans la zone superficielle par implantation ionique [104-105], des hauteurs de barrière proches de celles d'une homojonction ont été atteintes. L'intérêt pratique semble, toutefois, limité.

- Réalisation de siliciures. Un grand nombre de

HAUTEURS DE BARRIERE METAL-SILICIUM

SILICIURES ( $N$ et $P$ )

\begin{tabular}{|l|c|c|c|c|}
\hline \multirow{2}{*}{ Métal } & \multicolumn{2}{|c|}{$\begin{array}{c}\text { Earrière sur Si } \\
\text { (eV) }\end{array}$} & \multicolumn{2}{c|}{$\begin{array}{c}\text { Siliciures } \\
\text { (eV) }\end{array}$} \\
\hline \multirow{3}{*}{$\mathrm{Nf}$} & $\mathrm{N}$ & $\mathrm{P}$ & $\mathrm{N}$ & $\mathrm{P}$ \\
$\mathrm{Zrr}$ & $0,1-0,6$ & $0,58-0,95$ & 0,6 & 0,73 \\
$\mathrm{Rh}$ & & & & 0,55 \\
$\mathrm{Zn}$ & 0,64 & & 0,70 & 0,33 \\
$\mathrm{Co}$ & & & 0,55 & 0,53 \\
$\mathrm{Pt}$ & & & 0,64 & 0,40 \\
$\mathrm{Ni}$ & 0,9 & & 0,87 & 0,25 \\
$\mathrm{NiPt}(85 \% \mathrm{Pt})$ & & & 0,66 & 0,51 \\
$\mathrm{~W}$ & 0,66 & & 0,94 & \\
& & & 0,86 & \\
\hline
\end{tabular}

Fig. 28. - Hauteur de barrière de diodes Schottky et de siliciures sur silicium $\mathbf{N}$ et $\mathbf{P}$.

[Barrier heights of metal-silicon and silicides diodes.] métaux déposés sur du silicium porté à une température convenable peuvent former des siliciures [106-107]. Les hauteurs de barrière peuvent alors varier notablement avec la nature du siliciure réalisé. Quelques valeurs typiques sont reportées sur le tableau de la figure 28. Ces structures seraient intéressantes car elles permettent d'isoler la zone de jonction de la surface immédiate du semiconducteur, donc de la rendre moins sensible aux agents extérieurs. Malheureusement, les hauteurs de la barrière sont, d'une manière générale, plus faible que celles atteintes pour le même métal dans une structure Schottky.

Parmi les inconvénients des structures MS nous retiendrons donc essentiellement leur instabilité : sur de longues périodes, à des températures pouvant atteindre $100^{\circ} \mathrm{C}$ leur stabilité n'est pas assurée à l'heure actuelle.

5.2 CONTACT MÉTAL-ISOLANT-SEMiCONDUCTEUR. Des résultats nouveaux et très intéressants ont été obtenus au cours de ces deux dernières années avec des structures MIS : l'introduction d'un [108] film isolant de faible épaisseur (10-20 ̊̊) entre le métal et le semiconducteur permet de transformer le contact MS à porteurs majoritaires en une structure proche de l'homojonction, car à porteurs minoritaires, présentant des rendements de conversion intéressants. En effet, dans une telle diode, le courant d'émission thermoionique peut être réduit par toute ou partie des effets suivants résultant de la présence de l'isolant :

- accroissement de la hauteur de barrière;

- réduction de l'effet tunnel des porteurs majoritaires ;

- accroissement des états d'interface présentant une forte section efficace de capture des porteurs majoritaires ;

- réduction de la densité de porteurs majoritaires dans la zone superficielle du semiconducteur.

Plusieurs groupes [109-120] ont proposé des modèles tenant compte d'une partie de ces effets sur le fonctionnement et le rendement de ce type de cellule (12-13\%). En ce qui concerne ce dernier point, notons l'importance primordiale des traitements anti-réfléchissant pour ces films miroirs [121-131].

5.2.1 Couche isolante. - Les travaux tant théoriques qu'expérimentaux indiquent que les meilleurs résultats (Fig. 29) sont obtenus avec un film diélectrique d'épaisseur inférieure à $20 \AA$ Å. Réaliser de telles couches, stables, présentant des densités de défauts faibles même sur des aires importantes n'est pas simple, de sorte que les taux de réussite des premiers dispositifs de ce type étaient faibles. La persévérance de certaines équipes a permis des progrès notables, en particulier, par suite d'une meilleure compréhension des phénomènes physiques en jeu.

Différents types d'oxydes ont été employés (Fig. 30) :

- oxyde natif : si les premières couches de silicium s'oxydent aisément, il n'en est plus de même plus 


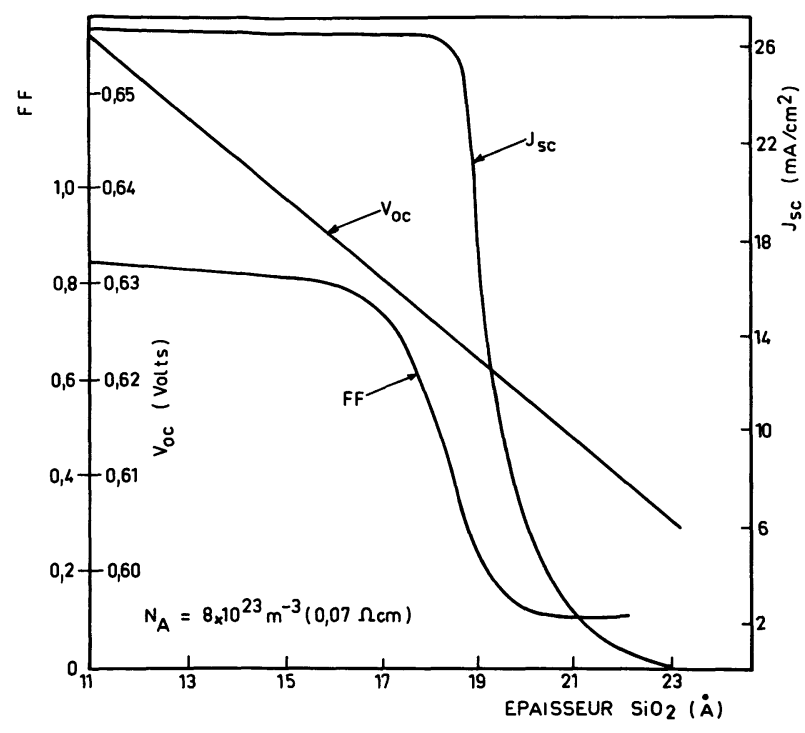

Fig. 29. - Effet d'une couche d'oxyde interfaciale sur la tension en circuit ouvert $V_{\mathrm{oc}}$, le courant photogénéré $I_{\mathrm{sc}}$ et le facteur de remplissage FF [119].

[Influence of the insulating interfacial layer on the open circuit voltage $V_{\mathrm{oc}}$, photogenerated current $I_{\mathrm{sc}}$ and fill factor FF [119].]

profondément où la pénétration de l'oxygène se fait plus difficilement, ce qui conduit à un oxyde déficient en $O$ dont la structure [132-133] est approximativement $\mathrm{SiO}_{0.4}$. Ceci introduit des niveaux donneurs à l'interface, préjudiciables aux cellules M-I-S sur $\mathrm{Si}$ de type $\mathbf{N}$, car réduisant la courbe des bandes en surface [126, 134]. Des niveaux accepteurs n'apparâ̂tront qu'en présence de radicaux $(\mathrm{OH})^{-}$[118]. De ce fait, les structures MIS pourront être réalisées plus aisément sur des cristaux de type $P$.

- Oxyde thermique. - L'oxydation thermique par voie sèche ou humide est utilisée largement dans l'industrie des dispositifs. Les problèmes qui se posent ici sont liés d'une part à la faible épaisseur d'oxyde nécessaire, donc difficile à contrôler sur de grandes

\begin{tabular}{|c|c|c|c|}
\hline Méthode & & Durée & Référence \\
\hline 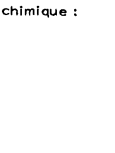 & $\begin{array}{l}\text { oxydation anodique } \\
\text { acide nitrique chaud } \\
\text { eau bouillante } \\
10 \% \mathrm{HF} \text { dans } \mathrm{H}_{2} \mathrm{O} \\
\mathrm{SiO}_{2} \text { dans } 40 \% \mathrm{HF} \\
{\left[\left(\mathrm{H}_{3} \mathrm{O}\right)_{2} \mathrm{SiF}_{6}\right]}\end{array}$ & $\begin{array}{l}8 \mathrm{~min} . \\
1 \mathrm{~min} . \\
1-2 \mathrm{~min} .\end{array}$ & $\begin{array}{l}{[121,122]} \\
{[121,123]} \\
{[121]} \\
{[124]} \\
{[125]} \\
{[125]}\end{array}$ \\
\hline evaporation: & de SiO à faible vitesse & & {$[123]$} \\
\hline thermique : & $\begin{array}{l}\text { air } 150^{\circ} \mathrm{C} \\
\text { air } 400^{\circ} \mathrm{C} \\
\text { air } 620^{\circ} \mathrm{C} \\
\text { oxygene sec } 420^{\circ} \mathrm{C} \\
\text { oxygène humide } 420^{\circ} \mathrm{C} \\
\text { oxygene } 515^{\circ} \mathrm{C} \\
\text { azote humide } 450^{\circ} \mathrm{C} \\
\text { azote }+ \text { oxygeme } 450^{\circ} \mathrm{C} \\
\text { vapeur d'eau } 700-900^{\circ} \mathrm{C}\end{array}$ & $\begin{array}{l}\text { 5-70 } \mathrm{h} . \\
5-60 \mathrm{~min} . \\
15-30 \mathrm{~min} . \\
10 \mathrm{~min} . \\
5-40 \mathrm{~min} . \\
12 \mathrm{~min} . \\
15-30 \mathrm{~min} . \\
10 \mathrm{~min} . \\
\text { 9q. } \mathrm{min} .\end{array}$ & $\begin{array}{l}{[126]} \\
{[127]} \\
{[125]} \\
\\
{[128]} \\
{[122]} \\
{[129]} \\
{[130]} \\
{[131]}\end{array}$ \\
\hline
\end{tabular}

Fig. 30. - Méthodes de formation de la couche d'oxyde interfaciale dans les diodes MIS.

[Various methods to prepare the thin insulating layer on an MIS structure.] surfaces, et au manque d'oxygène dans la couche d'oxyde d'épaisseur inférieure à $50 \AA \AA$ (voir ci-dessus) [135-140].

- Oxydation chimique. - L'acide nitrique, l'eau bouillante ont été employés, la structure de la couche est voisine de $\mathrm{SiO}_{0,8}-\mathrm{SiO}_{1,2}$ [141] pour des épaisseurs voisines de $30 \AA$. Des résultats intéressants ont été atteints par une solution $\left(\mathrm{H}_{3} \mathrm{O}\right)_{2} \mathrm{SiF}_{6}$ car l'attaque s'arrête d'elle-même pour une épaisseur juste optimale aux structures MIS et la présence de fluor réduit la densité des états d'interface.

- Evaporation de SiO. - La stœchiométrie des films dépend essentiellement de la pression au moment de l'évaporation et de la vitesse de dépôt. Pour un film d'épaisseur $1500 \AA$ déposé à $10^{-5}$ torr on obtient $\mathrm{SiO}_{1,8}$ et $\mathrm{SiO}_{1,2}$ respectivement pour des vitesses de 1 et $10 \AA / \mathrm{s}$. Ces valeurs passent à $\mathrm{SiO}_{1,3}$ et $\mathrm{SiO}$ pour les mêmes conditions dans un film de $200 \AA$ d'épaisseur [123].

5.2.2 Résultats. - Les tensions en circuit ouvert $V_{\text {oc }}$ obtenues par les divers groupes sont reportées sur la figure 31 . On notera que les meilleurs résultats sont enregistrés sur les matériaux de type $P$, en accord avec ce qui est indiqué plus haut. En fait, ces résultats sont très proches de ceux d'une homojonction. On peut donc penser que l'emploi de résistivités faibles et d'un champ arrière (« back surface field ॥) [144] pourront rendre ces structures tout à fait compétitives en ce qui concerne $V_{\text {oc }}$. Notons que sur des substrats polycristallins des valeurs de $540 \mathrm{mV}$ ont été atteintes [145].

\begin{tabular}{|c|c|c|c|c|c|}
\hline TYPE & $\begin{array}{l}\text { RESISTIVITE } \\
\text { 2.cm }\end{array}$ & METAL & COUCHE OBTENUE PAR & $v_{o c}$ & REFERENCE \\
\hline N & $\begin{array}{l}1-10 \\
0,1-0,2 \\
8-20 \\
5-10 \\
5-10 \\
1-10\end{array}$ & $\begin{array}{l}\text { Au } \\
\text { Au } \\
\text { Au } \\
\text { Au } \\
\text { Pt } \\
\text { Au }\end{array}$ & $\begin{array}{l}\text { evap. Sio } \\
\text { thermique } \\
\text { oxydation anodique } \\
\text { thermique } \\
\text { thermique } \\
\text { chimique }\end{array}$ & $\begin{array}{l}550 \\
440 \\
425 \\
420 \\
410 \\
400\end{array}$ & 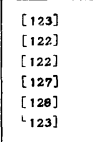 \\
\hline P & $\begin{array}{l}1 \\
0,1 \\
0,2 \\
2 \\
1 \\
1 \\
2-10 \\
3-15\end{array}$ & $\begin{array}{l}A 1 \\
A 1 \\
A 1 \\
C_{C}(+C U) \\
A 1 \\
\text { Ti } \\
A 1 \\
A 1\end{array}$ & 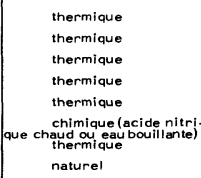 & $\begin{array}{l}615 \\
610 \\
600 \\
600 \\
560 \\
550 \\
470 \\
470\end{array}$ & 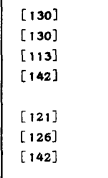 \\
\hline
\end{tabular}

Fig. 31. - Tension en circuit ouvert de diodes MIS préparées suivant différentes méthodes.

[Open circuit voltage $V_{\mathrm{oc}}$ of MIS structures prepared in different manners.]

- Les courants d'éclairement varient fortement dans la littérature (Fig. 32) sans doute par suite des traitements très divers utilisés et de la mise en œuvre de couches anti-réfléchissantes plus ou moins bien adaptées. En principe, ces structures devraient présenter une bonne réponse spectrale en I.R. (absence de traitements thermiques) et leur réponse U.V. n'est 


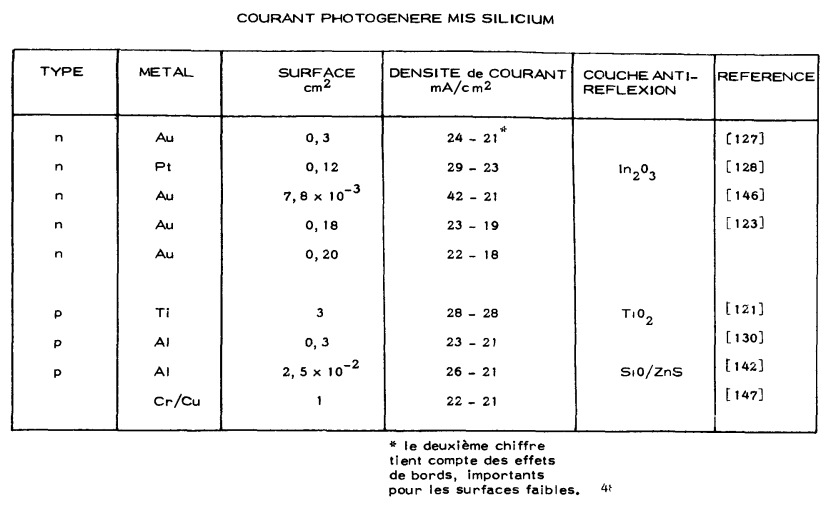

Fig. 32. - Courant photogénéré de diodes MIS, sans et avec la contribution des bords.

[Photogenerated current density for various MIS structures. On the smaller cells edge effects have been included (real area much larger than the metal contact).]

fonction que de l'épaisseur du métal et d'éventuelles couches d'interface perturbées. Sur des substrats polycristallins des densités de courant de $20 \mathrm{~mA} / \mathrm{cm}^{2}$ ont été enregistrées.

- Les valeurs des facteurs de remplissage atteignent celles des jonctions $\mathbf{P}-\mathbf{N}$ puisqu'elles se situent vers 0,75 [126-127].

Les résultats publiés dans la littérature semblent donc indiquer des possibilités tout à fait comparables pour ces structures par rapport aux homojonctions. Par contre, aucune information n'a été publiée à notre connaissance quant à leur stabilité à long terme, qui reste à prouver.

5.3 StRUCTURes mis a COUCHE D'INVERSION. Pour éviter la préparation de couches d'oxyde mince, il a été proposé récemment [149-152] d'employer des couches d'inversion en surface sous des électrodes de $\mathrm{TiO}_{x}$ ou $\mathrm{SiO}_{2}$ épaisses (qui servent en même temps de couches antiréfléchissantes) pour réaliser des cellules solaires. Des rendements intéressants, de l'ordre de $12 \%$ ont été publiés et il semble donc que les problèmes de résistance superficielle de ces couches aient pu être maîtrisés notamment par un dessin optimal de la grille collectrice.

5.4 HéTÉRostruCtURES : OXYDES D’ÉTAIN ET D'INDIUM. - Des barrières de potentiel peuvent être formées en déposant un semiconducteur à la surface $\mathrm{du}$ silicium sous certaines conditions. Celles-ci seront notamment :

- transparence pour les photons du spectre solaire absorbés dans le silicium. Sa largeur de bande interdite devra donc être supérieure à $3 \mathrm{eV}(\lambda>0,4 \mu)$;

- conductibilité élevée pour bien évacuer les charges créées par le rayonnement ;

- barrière de potentiel élevée pour accroître le rendement de conversion ;

- indice de réfraction voisin de 2 pour jouer le rôle de couche antiréfléchissante.
Deux matériaux remplissent bien ces conditions : l'oxyde d'étain $\left(\mathrm{SnO}_{2}\right)$ et l'oxyde d'indium $\left(\mathrm{In}_{2} \mathrm{O}_{3}\right)$ qui peuvent être déposés soit par évaporation, soit par pulvérisation ou par pulvérisation chimique (spray). Si l'oxyde d'étain est employé depuis très longtemps pour réaliser des verres conducteurs, ce n'est que depuis 3 ans environ qu'on l'utilise pour la préparation d'hétérojonctions. Les premiers travaux ont conduit à des rendements faibles, mais actuellement des valeurs de $10 \%$ ont été atteintes pour des surfaces de $1 \mathrm{~cm}^{2}$ $\left(V_{\mathrm{oc}} \approx 525 \mathrm{mV}, I \approx 30 \mathrm{~mA} / \mathrm{cm}^{2}, F F=0,60\right)$.

Dans le cas de $\operatorname{In}_{2} \mathrm{O}_{3}$ ces valeurs atteignent même $12 \%$ sur des aires de plusieurs $\mathrm{cm}^{2}$. En déposant par spray de l'oxyde d'indium dopé à l'étain des cellules ayant les propriétés suivantes ont été préparées : $V_{\mathrm{oc}}=500 \mathrm{mV}, I \approx 32 \mathrm{~mA} / \mathrm{cm}^{2}, F F=0,65$, $S=2 \mathrm{~cm}^{2}$, soit un rendement de $11 \%$. Cette technique est très économique et rapide [153-160].

Dans ces structures, le niveau de dégénérescence est très élevée dans la couche d'oxyde puisque l'étain introduit un dopage de $10^{21} \mathrm{~cm}^{-3}$ produisant pratiquement une structure MS ou MIS suivant le procédé de fabrication.

La stabilité à long terme de ces diodes n'a pas été abordée dans la littérature, mais on peut penser qu'elle est satisfaisante. L'absence de zone morte (fenêtre transparente), la facilité de réalisation de ces structures devraient constituer des atouts technologiques et économiques.

\subsubsection{Introduction des dopants en cours d'élabo-} ration des films. - Lorsque les films de silicium sont préparés par transport en phase vapeur, il sera aisé d'introduire les dopants en cours de croissance en ajoutant aux vapeurs ou gaz d'autres composés gazeux contenant le dopant $\left(\mathrm{BF}_{3}, \mathrm{~B}_{2} \mathrm{H}_{6}, \mathrm{PF}_{5}, \mathrm{PCl}_{5} \ldots\right)$. Cette technique est très courante dans l'industrie des semiconducteurs pour le dopage de couches épitaxiées ; récemment, plusieurs auteurs l'ont utilisée pour la préparation de cellules sur substrat polycristallin ou amorphe [88]. Lorsque ce dernier matériau est préparé par pulvérisation cathodique à partir de silicium solide, on pourra doper les couches en employant une matière première très dopée [93].

5.4.2 Implantation ionique. - De curiosité de laboratoires qu'elle était pendant longtemps, cette technique de dopage superficiel est, depuis peu de temps, passée à l'industrie électronique. Elle offre, trois avantages essentiels sur la diffusion thermique :

- introduction de dopants isotopiquement purs, grâce à l'analyse en masse par un aimant des faisceaux dont sont équipés les implanteurs ;

- concentration et distribution des dopants pouvant être contrôlées, des profils très variés pourront être réalisés ;

— processus effectué à température ambiante.

Dans le cas de cellules solaires, il convient d'ajouter : - zone morte d'entrée constante et de faible 
épaisseur, déterminée uniquement par la tension d'accélération des ions ;

- densité d'impuretés constante quelle que soit la nature du substrat, d'où la possibilité d'emploi de substrats polycristallins.

Les principaux inconvénients de l'implantation ionique sont :

- la nécessité de guérir les défauts introduits au cours du bombardement par des ions lourds de faible vitesse (probabilité de chocs nucléaires et de déplacement d'atomes importants) ;

— son coût élevé : alimentations stabilisées aimant d'analyse, lentilles électrostatiques pour maintenir la densité du faisceau (effet de charge d'espace).

Dans le cas des cellules solaires, il convient de rajouter :

- la nécessité de courants intenses pour couvrir rapidement des aires importantes ;

- le dopage est maximum en volume et non en surface (distribution gaussienne) les ions étant monocinétiques, d'où problème de résistance superficielle.

Cette technique fut employée dès 1966 pour la réalisation de cellules solaires [161-163] et des rendements de $11 \%$ furent atteints dès cette époque, après un recuit thermique des dommages. Récemment, elle a été reprise par plusieurs groupes [164-167], la guérison des défauts étant obtenue par recuit thermique ou par un faisceau d'électrons accélérés balayant la surface implantée [166]. Dans ce dernier cas 26 secondes sont nécessaires pour introduire $10^{15} \mathrm{~cm}^{-2}$ dopants (courant $200 \mu \mathrm{A}$ ) sur une surface de $2 \times 2 \mathrm{~cm}$. Pour implanter en ligne avec la machine de production de silicium EFG à cinq films simultanés, au moins autant d'implanteurs à courant élevé seraient nécessaires d'où un coût probablement trop élevé.

5.4.3 Dopage superficiel. Recristallisation par laser. - Nous avions indiqué plus haut l'emploi d'un faisceau laser pour recristalliser des films polycristallins. On verra ici que les faisceaux laser peuvent jouer un rôle intéressant dans l'élaboration des barrières de potentiel. Nous pensons, en effet, que les cellules industrielles, pour atteindre des coûts compétitifs,

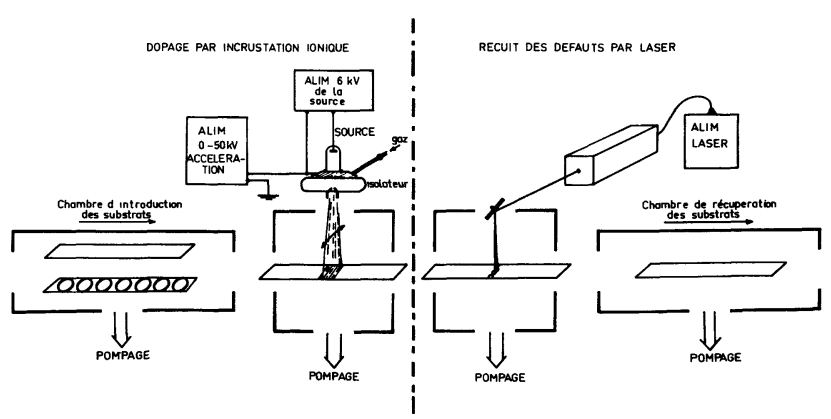

Fig. 33. - Schéma de principe d'une installation de dopage par incrustation d'ions et de recuit par laser [197].

[Schematic of an apparatus for continuous implantation and defect annealing by laser of the cell potential barrier [197].] doivent être produites d'une façon automatique, en continu. Il convient alors de supprimer les traitements chimiques de décapage, masquage..., ce qui interdit probablement l'emploi de la diffusion thermique. Il serait alors commode d'effectuer l'ensemble des opérations par des faisceaux ioniques et photoniques, plus faciles à contrôler automatiquement.

Pour atteindre cet objectif, nous avons proposé la procédure schématisée sur la figure 33 comprenant essentiellement deux étapes pour la réalisation de la barrière de potentiel (ou le contact ohmique) : une phase de dépôt des impuretés en surface - une phase d'activation des dopants par un recuit laser.

a) Dépôt des impuretés en surface - incrustation d'ions accélérés : Il s'agit en fait d'une implantation ionique très simplifiée ne comportant ni aimant, ni tensions stabilisées. On réalise un plasma par décharge dans un gaz comportant le dopant, par exemple $\mathrm{BF}_{3}$ (Fig. 34) puis on extrait par une tension convenable les ions atomiques $\left(\mathrm{B}^{+}\right)$et moléculaires $\left(\mathrm{BF}_{3}^{+}, \mathrm{BF}_{2}^{+} \ldots\right)$ chargés positivement pour les accélérer à la tension voulue et les envoyer finalement sur le silicium défilant devant ce faisceau. Contrairement à l'implantation ionique, la distribution des dopants ne sera plus gaussienne, mais elle s'étendra de la jonction stœchiométrique (formée par l'élément le plus léger, ici le bore) à la surface. De plus, tous les ions participant au bombardement, on aura des densités de courant importantes $\left(\approx 1 \mathrm{~mA} / \mathrm{cm}^{2}\right)$ sans effet notable de charge d'espace, puisque la structure de l'accélération est très courte. La faisabilité de cette technique a été prouvée $[164,168]$.

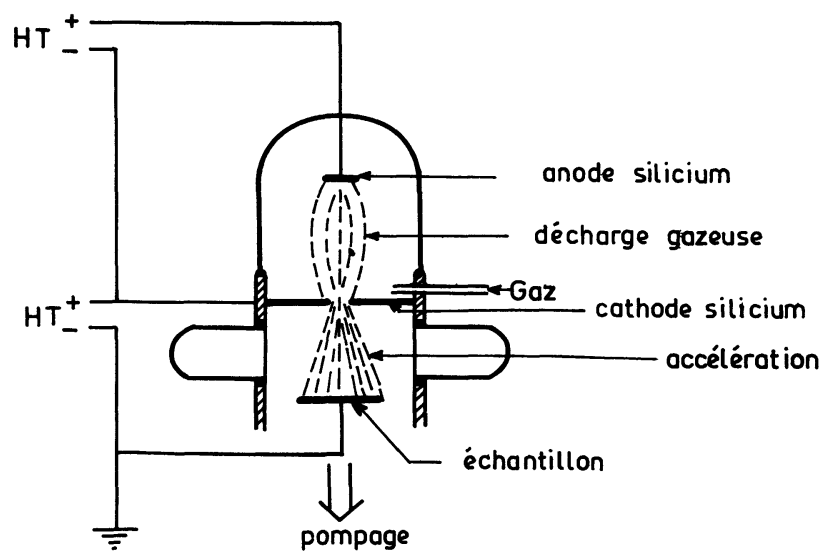

Fig. 34. - Schéma de principe de l'implanteur ionique ne comportant qu'une source d'ions par décharge gazeuse suivie d'une postaccélération des ions extraits.

[Schematic of a simplified ion implantation machine without any magnet.]

- Dépôt d'amas de dopants ou de silicium dopé (cluster). Pour accroître encore les densités de courants ioniques, tout en réduisant les dommages il est possible d'évaporer soit le dopant seul soit le silicium 
dopé puis, par une tuyère de forme spéciale de condenser un grand nombre d'atomes (100-1 000) en un amas (cluster) qui est finalement ionisé une seule fois, par un canon à électrons ou à argon. Cet amas sera ensuite accéléré à la tension souhaitée pour se briser finalement à la surface du silicium, chaque atome n'emportant qu'une faible énergie de celle du cluster (Fig. 35). Cette méthode a été employée auparavant [169-171] pour réaliser des semiconducteurs en couches minces.

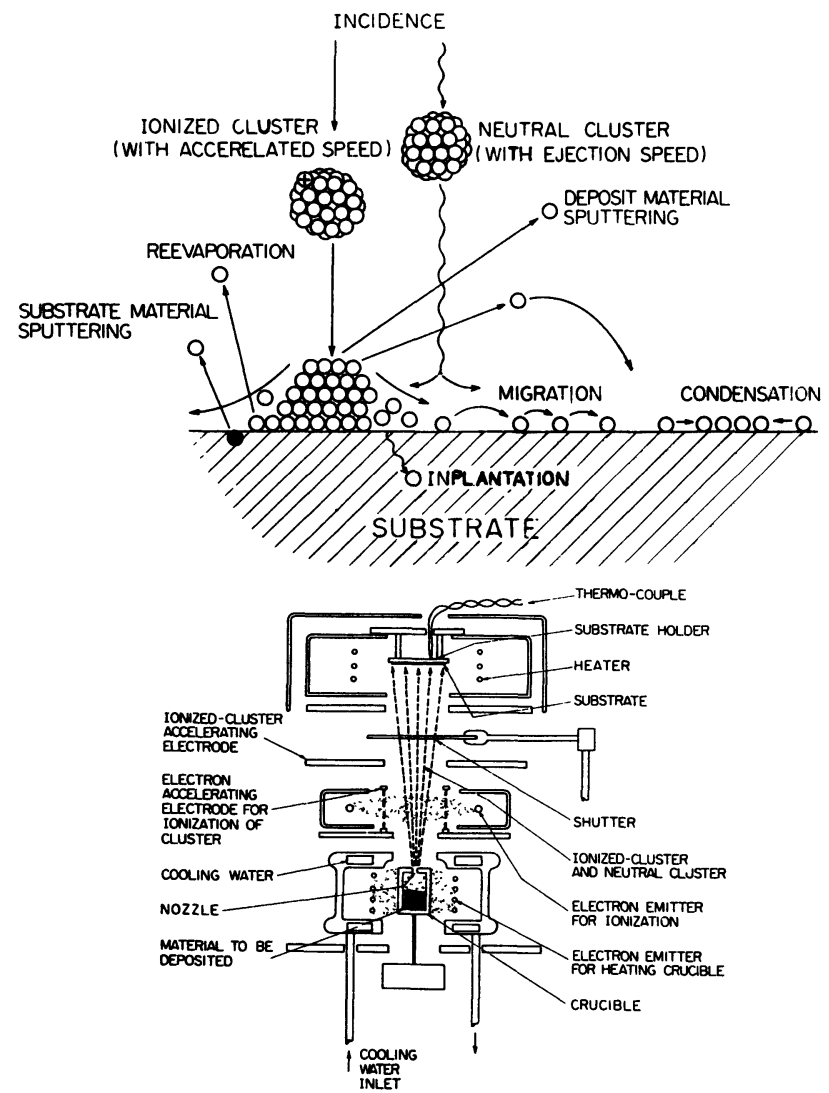

Fig. 35. - Principe d'une source cluster [171].

[Schematic of a cluster ion source [171].]

- Dépôt d'un film de silicium dopé en surface par évaporation, pulvérisation cathodique, voire simple dépôt d'un métal dopant.

Fig. 36b. - Spectre de rétrodiffusion de particules ${ }^{4} \mathrm{He}^{+}$d'énergie $1 \mathrm{MeV}$ en condition et hors canalisation d'une surface de silicium bombardée par décharge de $\mathrm{BF}_{3}$ de $25 \mathrm{keV}$ avant et après irradiation laser.

[Same analysis for $25 \mathrm{keV}$ implantation followed by a laser annealing the particles being analysed under normal geometry conditions.]

Fig. 36c. - Expérience identique à celle de la figure $36 b$ sauf que l'observation des particules rétrodiffusées se fait sous incidence rasante.

[Same conditions as in figure $36 b$ but for glancing angle geometry.]

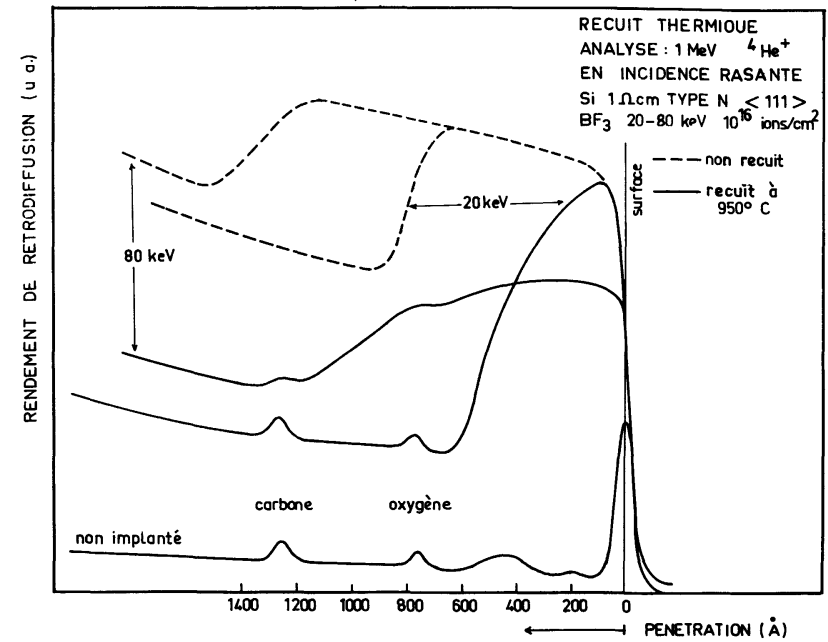

Fig. 36a. - Spectre de rétrodiffusion en condition et hors canalisation (channelling) et sous incidence rasante (glancing angle geometry) de particules ${ }^{4} \mathrm{He}^{+}$d'énergie $1 \mathrm{MeV}$ d'une surface de silicium bombardée par décharge de $\mathrm{BF}_{3}$ à 20 et $80 \mathrm{keV}$ avant (pointillés) et après recuit thermique à $950^{\circ} \mathrm{C}$ pendant $30 \mathrm{~min}$

[Backscattering spectra in random and channelling conditions of $1 \mathrm{MeV}{ }^{4} \mathrm{He}^{+}$ions on a $\mathrm{BF}_{3}$ glow discharge implantation of 20 and $80 \mathrm{keV}$ (dashed lines); effect of thermal annealing at $950^{\circ} \mathrm{C}$ for $30 \mathrm{~min}$. The analysis is performed under glancing angle geometry.]

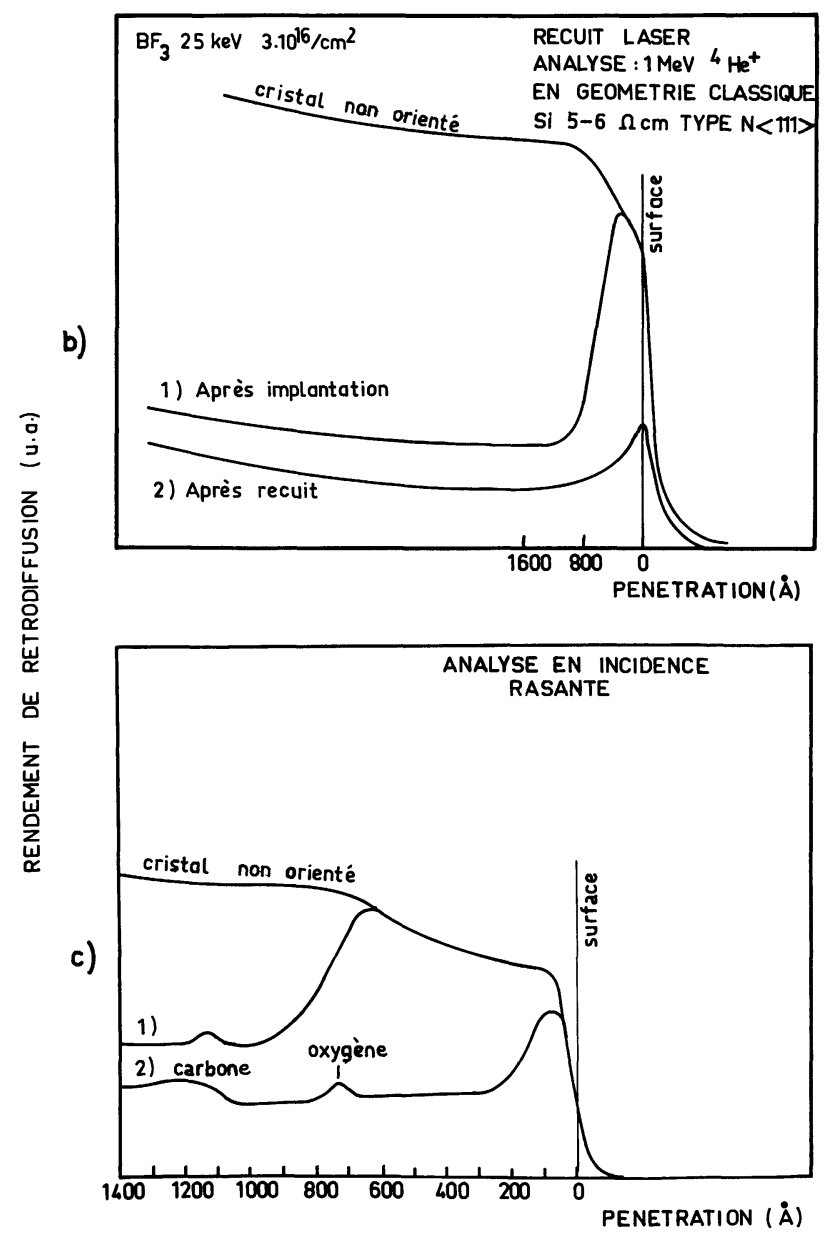


b) Activation des impuretés. - Récemment [172-191], on a constaté qu'une impulsion émise par un laser de puissance pouvait modifier considérablement les propriétés des surfaces des semiconducteurs, notamment :

- recristalliser une couche superficielle d'un cristal rendu amorphe par implantation ionique. Il suffit, en effet, d'une impulsion de puissance $10^{7} \mathrm{~W}$, de durée 10-20 ns pour restaurer la cristallinité beaucoup plus efficacement qu'un traitement thermique de longue durée et à haute température (Fig. 36) ;

- redistribuer complètement les impuretés implantées dans la zone atteinte par le flash laser (Fig. 37). Ceci est particulièrement intéressant dans notre cas,
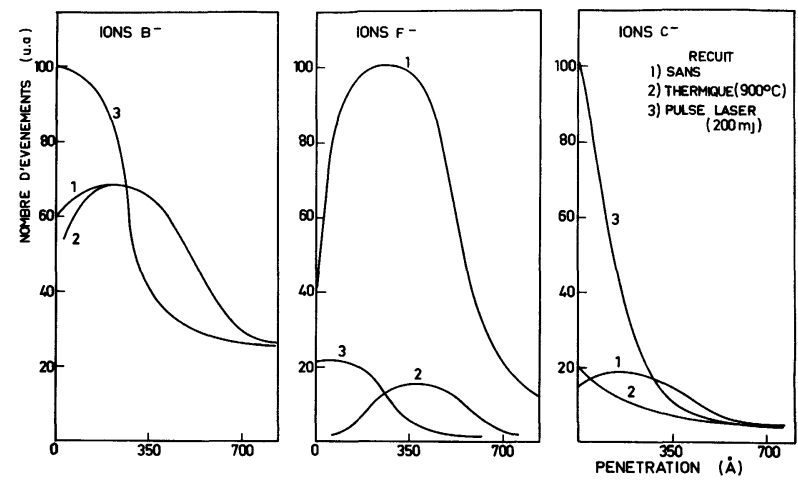

Fig. 37. - Profils des ions bore, fluor et carbone au voisinage de la surface de silicium bombardée par décharge de $\mathrm{BF}_{3}(25 \mathrm{keV})$ avant et après recuit thermique et après irradiation laser $(200 \mathrm{~mJ})$.

[Distribution of boron, fluorine and carbon as measured by SIMS in close surface vicinity immediately after $25 \mathrm{keV} \mathrm{BF}_{3}$ glow discharge, after thermal annealing and laser irradiation $(200 \mathrm{~mJ})$.]

puisque la distribution de dopants sera plus uniforme encore de la jonction stœchiométrique à la surface ;

- recristalliser des couches amorphes déposées sur un substrat ou en contact avec un film cristallin ;

- créer des alliages à partir de couches métalliques simplement évaporées sur le semiconducteur.

Les mécanismes physiques en jeu ne sont pas clairement établis à l'heure actuelle, mais vu les coefficients de diffusion des impuretés durant le flash $\left(D \approx 10^{-3} \mathrm{~cm}^{2} / \mathrm{s}\right)$ on peut penser que la surface des semiconducteurs est fondue momentanément. La plage de puissance optimale n'est pas clairement définie, mais il est certain qu'il existe un seuil minimal (de l'ordre de quelque $10^{6} \mathrm{~W}$ ) pour la recristallisation et une valeur maximale au-delà de laquelle de nouveaux défauts apparaissent.

Expérimentalement on emploie des lasers émettant entre 0,6 et 1,1 $\mu$, soit des flashs de durée 1-20 ns de grande surface, soit des faisceaux continus $(\approx 15 \mathrm{~W})$ focalisés et balayant la surface à traiter.

Cette technologie est en pleine évolution à l'heure actuelle et son impact définitif ne peut encore être évalué.

En résumé, il apparaît clairement que de nombreuses possibilités existent en dehors de la diffusion thermique, certaines pouvant être mises en œuvre très rapidement (hétérostructure $\operatorname{In}_{2} \mathrm{O}_{3}$ ) et on peut se demander pourquoi elles ne le sont pas, d'autres nécessitent encore des travaux de recherches avant de pouvoir être installées en ligne avec les unités de fabrication du silicium.

6. Conclusion. - Dans cet exposé nous avons cherché à nous limiter aux aspects scientifiques et techniques des problèmes et de n'accorder qu'une très faible attention aux questions économiques. Dans la réalité leur impact est déterminant. De ce point de vue trois étapes essentielles pourront être distinguées :

- actuellement l'industrie française occupe une place de choix dans la compétition internationale, grâce à une expérience très longue ;

- vers 1980-82 les possibilités de réduction des coûts des méthodes actuelles auront atteint leur palier. Des problèmes sérieux peuvent alors se présenter. En effet, il est clairement établi que le prix d'un produit décroît quand sa production croît; dans le cas des dispositifs semiconducteurs cela a maintes fois été vérifié et les prévisions pour les piles solaires ne feront pas exception (Fig. 38). Par conséquent, pour rester compétitive, l'industrie nationale aura besoin d'un fort accroissement de la production, sinon elle est définitivement dépassée par les prix étrangers, où une stimulation du marché existe (Fig. 39). Toutefois, il faut signaler que la courbe d'apprentissage ne tient pas compte d'innovations technologiques majeures ;

- vers 1985 les technologies nouvelles seront probablement opérationnelles. Une compétition sévère est engagée dès à présent non seulement pour la réalisation des cellules et panneaux mais encore pour la mise au point de nouveaux procédés de préparation de silicium de qualité solaire. Il convient de préparer dès à présent cette échéance.

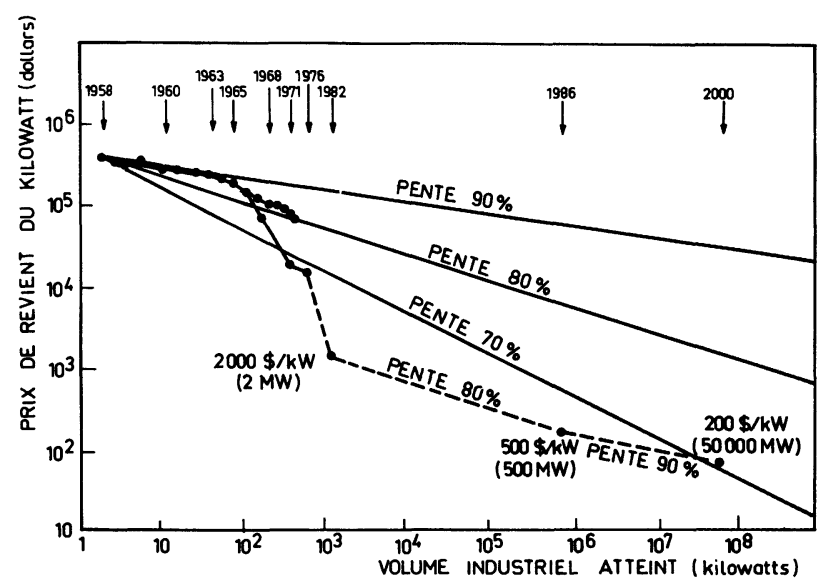

Fig. 38. - Estimation ERDA de l'évolution du prix de revient du kilowatt photovoltaique en fonction du volume industriel atteint pour différents taux d'apprentissage [192, 198].

[Cost per $\mathrm{kW}$ of solar photovoltaic electricity, as estimated by ERDA, as a function of total production for various possibilities described in Ref. [192] and [198].] 


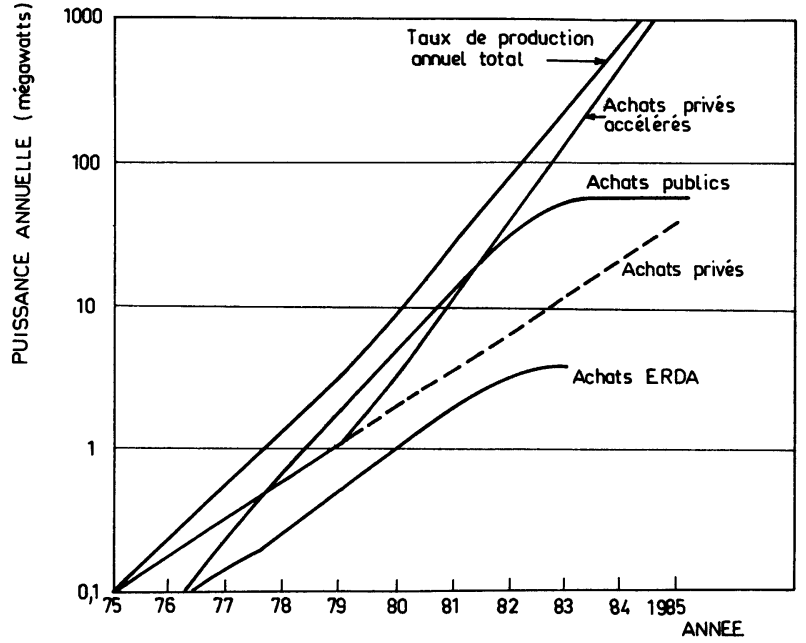

Pour terminer, mentionnons qu'aux USA les prix (1975) ont passé de 21 \$ en 1976 à 11 \$ actuellement, la presse faisant même mention de $6 \$$ par watt crête pour une installation de $362 \mathrm{~kW}$ à fournir en 1979.

Fig. 39. - Estimation ERDA des puissances photovoltaïques annuelles installées aux USA pour différentes hypothèses indiquées sur la figure $[192,198]$

[Expected photovoltaïc power installation in USA for the next years, as expected by ERDA.]

\section{Bibliographie}

\section{GÉNÉRALES}

[1] Eleventh IEEE Photovoltaic Specialists Conference (édité par IEEE) 1975.

[2] Twelfth IEEE Photovoltaïc Specialists Conference (édité par IEEE) 1976

[3] Photovoltaic Solar Energy Conference, CEE Luxembourg (1977) (D. Reidel Publishing Co Dodrecht, Hollande) 1977.

[4] Electricité Solaire, Toulouse ed. CNES Toulouse, 1976.

[5] Acta Electron. $20(1977) n^{\text {os }} 1$ et 2.

[6] BRissot, J. J., Réf. [5], p. 101.

[7] Lorenzini, R. E., NefF, F. S., Blair, D. J., Solid State Techn. 17 (1974) 33.

[8] PotTeR, J. J., Brevets US 875/672, 1905/7.

[9] Lauvray, H., Salles, Y., Réf. [3], p. 92.

[10] Hill, D. E., Gutsche, H. W., Wang, M. S., Gupta, H. P., TuCKER, W. E., Dowdy, J. D., Crepin, R. J., Réf. [2], p. 112.

[11] Hunt, L. P., Dosaj, V. D., Mc Cormick, J. R., Crossman, L. D., Réf. [2], p. 125 .

[12] WaKefield, G. F., Maycock, P. D., Réf. [2], p. 49.

[13] Kane Evan, O., Phys. Rev. 131 (1963) 79.

[14] Morgan, T. N., Phys. Rev. 139 (1965) A 343.

[15] Michel, J., Mircea, A., Acta Electron. 18 (1975) 311.

[16] Mandelkorn, J., Camneck, J. H., Réf. [2], p. 36.

[17] LiNDMAYER, J., Réf. [3], p. 76.

[18] Haynos, J., Allison, J., Arndt, R., Meulenberg, A., Photovoltaïc Power Generction (DGLR Köln ed.) 1974, 487.

[19] Lindmayer, J., Allison Comsat, J. F., Tech. Rev. 3 (1973) $\mathrm{n}^{\circ} 1$

[20] Baraona, C. R., Brandhorst, H. W., Réf. [2], p. 44.

[21] WiSE, J. F., U.S. Patent 3.690.953 et 579.801.

[22] Rahilly, W. P., 9th IEEE Photovoltaic Specialists Conf (1972) IEEE ed. p. 44

[23] Lloyd, W. W., Réf. [1], p. 349.

[24] LindMAYeR, J., Réf. [2], p. 30.

[25] Arndt, R. A., Allison, J. F., Haynos, J. G., Meulenberg, A., Réf. 1 p. 40 et Intern. Conf. on Photovoltaïc Power Generation, Hamburg (1974) ed. DGLR.

[26] Industrial Research, février 1978, p. 38

[27] Giszek, T. F., J. Appl. Phys. 47 (1976) 440.

[28] Bates, H. E., 9th Photovoltaïc Specialists Conference (ed. IEEE) (1972), p. 386.

[29] Ravi, K. V., Mlavski, A. I., Heliotechnique et Development ed. M. H. Kettani, J. Soussou (publi. Development Analysis, Associates Inc. Cambridge USA) 1976.
[30] Schwartz, J. C., J. Electron. Mater. 4 (1975) 255

[31] Ravi, K. V., J. Cryst. Growth 39 (1977) 1, J. Electrock. Soc. 20 (1973) 533.

[32] Chalmers, B., Labelle, H. E., Mlavsky, A. I., J. Cryst. Growth 13 (1972) 84.

[33] Bates, H. E., Jewett, D. N., White, V. E., IEEE Photovoltaic Specialists Conf. (ed. IEEE) 1973, p. 197.

[34] Ravi, K. V., Serreze, H. B., Bates, H. E., Morrison, A. D., JewetT, D. N., Ho, J. C. T., Réf. [1], p. 280.

[35] RaVI, K. V., Wald, F. V., Gonsiorawski, R., RaO, H., Garone, L. C., Ho, J. C. T.. Bfi I. R. O.. Réf. [2]. p. 182.

[36] RiCARD, J., Réf. [3], p. 882.

[37] Lesk, I. A., Bagdadi, A., Gurtler, R. W., Ellis, R. J., Wise, J. A., Coleman, M. G., Réf. [2], p. 173.

[38] Bennet, A. I., Longini, R. I., Phys. Rev. 116 (1959) 53.

[39] Dermatis, S. N., Faust, J. W., J. Electrochem. Soc. 107 (1960) 188

[40] Dermatis, S. N., Faust, J. W., IEEE Comm. Electron. 65 (1963) 94.

[41] Barrett, D. L., Myers, E. M., Hamilton, D. R., Bennet, A. I., J. Electrochem. Soc. 118 (1971) 952.

[42] Seidensticker, R. G., Réf. [2], p. 299.

[43] Gangullée, A., Ho, P. S., Tu, K. N., Thin Solid Films 25 (1975)

[44] Ziegler, J. F., MAYer, J. W., Chu, W. K., New Uses of Low Energy Accelerators, ed. J. F. Ziegler (Plenum Press) 1975, ch. 2.

[45] Sankur, H., Mc Caldin, J. O., Devaney, J., Appl. Phys. Lett. 22 (1973) 64.

[46] Hirahi, A., Lugujo, E., Mayer, J. W., J. Appl. Phys. 43 (1972) 3643

[47] Herd, S., Chaudhari, P., Brosky, M. H., J. Non-Crystal Solids 7 (1972) 309.

[48] Nakamura, K., Olowolafe, J. O., Lau, S. S., Nicolet, M. A., Mayer, J. W., Shima, R., J. Appl. Phys. 47 (1976) 1278.

[49] Fern, A. M., Mc Caldin, J. O., Proc. IEEE 60 (1972) 1018

[50] Sankur, H., Mc Caldin, J. O., Appl. Phys. Lett. 22 (1973) 64.

[51] Ottaviani, G., Sigurd, D., Marello, V., Caldin, J. O., MAYER, J. W., Science 180 (1973) 948.

[52] Sigurd, D., Ottaviani, G., Marello, V., Mayer, J. W., Mc Caldin, J. O., J. Non-Crystal Solids 12 (1972) 135, J. Appl. Phys. 45 (1974) 1730.

[53] Sigurd, D., Ottaviani, G., Canali, C., Majni, G., J. Appl. Phys. 47 (1976) 627. 
[54] Majni, G., Ottaviani, G., Appl. Phys. Lett. 31 (1977) 125.

[55] Majni, G., Ottaviani, G., StUCK, R., à paraître J. Thin Films (1978).

[56] FisCHER, H., Réf. [3]. p. 52.

[57] LiNDMAYER, J., Réf. [3], p. 76; Réf. [2], p. 82.

[58] Hovel, H. J., vol. XI Semiconductors and Semimetals.

[59] Soclov, S. I.. ICES, P. A., Réf. [2], p. 978.

[60] Gliberman, A. Y., Zeitseva, A. K., Landsman, A. P., Sov. Phys. Semicond. 2 (1968) 1583.

[61] Haigh, A. D., Réf. [4], p. 183.

[62] FANG, P. H., Annual Report NSF/RANN/SE/GI-34975/PR/ $72 / 4$.

[63] Ephrath, L. M., J. Electr. Mat. 4 (1975) 1207.

[64] Feldman, C., Réf. [2], p. 100.

[65] Chu, T. L., Mollenkopf, H. C., Chu, S. S., J. Electrochem. Soc. 122 (1975) 1681.

[66] ForRat, F., Brevet français 7426521 (1974).

[67] Hall, R. N., Gordon Conference on Crystal Growth New Hampshire (1976) USA

[68] CHU, T. L., IEEE Trans. El. Dev. ED 24 (1977) 4.

[69] Saitoh, T., Japan J. Appl. Phys. 16 (1977) 413.

[70] Warabisako, T., Saitoh, T., IEEE El. Dev. ED 24 (1977) 4.

[71] KIM, H. J., J. Electrochem. Soc. 119 (1972) 1394.

[72] Girault, R., Chevrier, F., Houllie, A., Bougnot, G., 1976, Crystal Growth and Materials (Zurich) KALDIS, E., SCHEEL, H. J. ed. (North Holland) 1976.

[73] BRISSOT, J. J., Brevet 912052 (1962).

[74] Brissot, J. J., Belouet, C., Rev. Intern. Héliotechnique (1975) 42.

[75] Belouet, C., Brissot, J. J., Martres, R., Réf. [4], p. 191.

[76] Belouet, C., Brissot, J. J., Martres, R., NGo Tichphuoc, Réf. [3], p. 164.

[77] BRIsSOT, J. J., 1976, Crystal Growth and Materials, ed.E.Kaldis, H. Scheel (North Holland) 1978.

[78] Fabre, E., BaUdet, Y., Réf. [3], p. 178.

[79] Heaps, J. D., KacioleK, R. B., Zook, J. D., Scott, M. W., Réf. [2], p. 147.

[80] WACKER-CHEMITRONIC, Brevet allemand, p. 2508.803 .3 (1975).

[81] Fischer, H., Pschunder, W., Réf. [2], p. 86.

[82] LindMAYER, J., Réf. [2], p. 82.

[83] FisCher, H., Réf. [3], p. 52.

[84] Proceedings of the 7th Intern. Conf. on Amorphous and Liquid Semiconductors (1977) ed. W. E. Spear, CICL University of Edinburgh.

[85] Spear, W. E., Adv. Phys. 26 (1977) 811.

[86] Lewis, A. J., Connell, G. A. N., Paul, W., Pawlik, J. R., Temkin, R. J., Tetrahedrally Bonded Amorphous Semiconductor, ed. M. Brodsky, S. Kirpatrik, D. Weaire (New York, AIP), p. 27.

[87] Paul, W., Lewis, A. J., Connell, G. A. N., Moustakas, P. D., Solid State Commun. 20 (1976) 969.

[88] Carlson, D. E., Wronski, C. R., Appl. Phys. Lett. 28 (1976) 671 ; Solid State Commun. 23 (1977) 421

[89] Carlson, D. E., Wronski, C. R., Daniel, R. E., Appl. Phys. Lett. 29 (1976) 602 ; réf. [2], p. 893.

[90] Carlson, D. E., IEEE Trans. Electr. Dev. 24 (1977) 449.

[91] RoNSKI, C. R. W., IEEE Trans. Electr. Dev. 24 (1977) 351.

[92] Brodsky, M. H., Cardona, M., Cuomo, J. J., IBM Report 6485 (1977).

[93] Thompson, M. J., Allison, J., Alkaisi, M. M., Barber, S. J., Réf. [3], p. 231.

[94] Debney, B. T., Réf. [3], p. 216.

[95] Ponpon, J. P., Siffert, P., J. Appl. Phys. 47 (1976) 3248.

[96] Nombreuses références voir p. ex. SzE, S. M., Physics of Semiconductor Devices (Wiley) 1969.

[97] SIFFert, P., Coche, A., IEEE Trans. Nucl. Sci. NS 11 (1964) 244.

[98] Ponpon, J. P., Grob, J. J. A., Stuck, R., Siffert, P., Nucl. Instrum. Meth. 149 (1978) 647.

[99] Michaelson, H. B., J. Appl. Phys. 48 (1977) 4729; IBM Journal of Research 22 (1978) 72.
[100] Best, J. S., Mc Caldin, J. O., MC Gill, T. C., Mead, C. A., Mooney, J. B., Appl. Phys. Lett. 29 (1976) 433.

[101] Caldin, J. O., Mc Gill, T. C., Mead, C. A., Phys. Rev. Lett. 36 (1976) 56.

[102] Scranton, R. A., Mooney, J. B., Mc Caldin, J. O., MC Gill, T. C., Mead, C. A., Appl. Phys. Lett. 29 (1976) 47.

[103] Scrantoin, R. A., J. Appl. Phys. 48 (1977) 3838.

[104] Shannon, J. M., Appl. Phys. Lett. 25 (1974) 75; 24 (1974) 488.

[105] Ponpon, J. P., Sifrert, P., J. Physique Lett. 36 (1975) L-2149.

[106] NowotNy, H., Silicides and Borides (1972) MTP Intern. Review of Science Inorg. Chem. Series vol. 10, ch. 5.

[107] Sundström, K. E., Peterson, S., Tove, P. A., Rapport UPTEC 73 29C (1973) Université d'Uppsala.

[108] StiRn, R. J., Yeh, Y. C. M., Appl. Phys. Lett. 27 (1975) 95.

[109] Charlson, E. J., Lien, J. C., J. Appl. Phys. 46 (1975) 9.

[110] Fonash, S. I., J. Appl. Phys. 46 (1975) 1286.

[111] Singh, R., Shewchun, J., Appl. Phys. Lett. 28 (1976) 512.

[112] Viktorovich, P., Kamarinos, G., Even, P., C.R. Hebd. Sean. Acad. Sci. 283 B (1976) 119, Réf. [2], p. 870.

[113] Saint-Pierre, J. A., Singh, R., Shewchun, J., Loferski, J. J., Réf. [2], p. 847.

[114] Olsen, L. C., Réf. [2], p. 854.

[115] Childs, R., Fortuna, J., Geneczko, J., Fonash, S. J., Réf. [2], p. 862.

[116] KlimpKe, C., LANDSberg, P. T., Réf. [2], p. 868.

[117] De Visschere, P., Pauwels, H., Réf. [3], p. 330.

[118] Kipperman, A. H., Backerra, S. C. M., MaAsKamp, H. J., Réf. [3], p. 956.

[119] Green, M. A., King, F. D., Shewchun, J., Solid State Electr. 17 (1974) 551

[120] Green, M. A., Godfrey, R. B., Appl. Phys. Lett. 29 (1976) 610.

[121] Fabre, E., Michel, J., Baudet, Y., Réf. [2], p. 904.

[122] Childs, R., Fortuna, J., Genechzo, J., Fonash, S. J., Réf. [2], p. 862.

[123] Ponpon, J. P., Siffert, P., Réf. [2], p. 900 et J. Appl. Phys. 47 (1976) 3248.

[124] Kipperman, A. H. M., Omar, M. H., Appl. Phys. Lett. 28 (1976) 620.

[125] Kipperman, A. H. M., Omar, M. H., Réf. [3], p. 957.

[126] Pulfrey, D. L., Sol. State Electr. 20 (1977) 455.

[127] Lillington, D. R. et Townsend, W. C., Appl. Phys. Lett. 28 (1976) 97

[128] Matsumami, H., Matsumoto, S., Tanako, T., Réf. [2], p. 917.

[129] Van Allen, P., Thomas, R. E., van Overstraeten, R., Réf. [2], p. 907.

[130] Green, M. A., Godfrey, R. B., Davies, L. W., Réf. [2], p. 896.

[131] Shewchun, J., Green, M. A., KIng, F. D., Solid State Electr. 17 (1974) 563.

[132] Harrington, W. L., Honig, R. E., Goodman, A. M., Williams, R., Appl. Phys. Lett. 27 (1975) 644.

[133] Van der Meulen, Y. J., J. Vac. Sci. Techn. 11 (1974) 985.

[134] Viktorovich, P., Kamarinos, G., Even, P., Fabre, E., à paraître Phys. Status Solidi (1978).

[135] Clarke, R. A., Tapping, R. L., Hopper, M. A., Young, L., J. Electrochem. Soc. 122 (1975) 1347.

[136] Raider, S. I., Flitsch, R., J. Vac. Sci. Techn. 13 (1976) 58.

[137] Johannessen, J. S., Spicer, W. E., Strausser, Y. E., Appl. Phys. Lett. 27 (1975) 452; J. Appl. Phys. 47 (1976) 3028.

[138] Harrington, W. L., Honig, R. E., Goodman, A. M. Williams, R., Appl. Phys. Lett. 27 (1975) 644.

[139] VAN DeR Weg, W. F., Rad. Eff. 17 (1973) 245.

[140] Offermann, P., J. Appl. Phys. 48(1977) 1890.

[141] Buck, T. M., Wheatley, G. H., Surf. Sci. 33 (1972) 35.

[142] Anderson, W. A., Kim, J. K., Delahoy, A. E.. IEEE ED 24 (1977) $4,453$.

[143] Charlson, E. J., Lien, J. C., J. Appl. Phys. 46 (1975) 3982.

[144] Green, M. A., Godfrey, R. B., Réf. [3], p. 299.

[145] Anderson, W. A., Rapport NSF, AER 73-03197 (1977), Réf. [3], p. 308.

[146] SheVenock, S., Fonash, S. J., Geneczko, J., Techn. Digest IEEE Int. Electr. Dev. Meeting (1975). 
[147] Anderson, W. A., Vernon, S. M., Delahoy, A. E., Kim, J. K., Mathe, P., J. Vac. Sci. Techn. 13 (1976) 1158.

[148] Pulfrey, D. L., à paraître IEEE E. D.

[149] Call, R. L., Rapport Contrat JPL 953461 (1973).

[150] Salter, G. C., Thomas, R. E., Solid State Electron. 20 (1977) 95.

[151] Norman, C. E., Thomas, R. E., Réf. [2] (1976) 993 ; id. p. 907.

[152] Van Halen, P., Mertens, R., van Overstraeten, R., Thomas, R. E., Réf. [3], p. 280.

[153] Lai, S. W., Fransz, S. L., Kent, G., Anderson, R. L. Réf. [1], p. 398.

[154] Dubow, J. B., Burk, D. E., Sites, J. R., Proc. Int. Electr. Dev. IEDM (1975) 230

[155] Anderson, R. L., Appl. Phys. Lett. 27 (1975) 691;

Perotin, M., Szepessy, L., Manifacier, J. C., Parot, C., Filcard, J. P., Savelli, M., Réf. [4], p. 481.

[156] Dubow, J. B., Burk, D. E., Sites, J. R., Appl. Phys. Lett. 29 (1976) 494.

[157] Kato, H., Yoshida, A., Arizumi, T., Japan J. Appl. Phys. 15 (1976) 1819.

[158] Mizrah, T., Adler, D., Appl. Phys. Lett. 29 (1976) 682.

[159] Matsunami, H., Oo, K., Ito, H., Tanaha, T., Japan J. Appl. Phys. 14 (1975) 915.

[160] Manifacier, J. C., Szepessy, L., SAVelli, M., Réf. [3], p. 289.

[161] Gosev, V. M., Timov, V. V., Guseva, M. I., KurinnYı, V. I., Sov. Phys. Solid State 7 (1966) 1673.

[162] Gusev, V. M., Zadde, V. V., Landsman, A. P., Titov, V. V., Sov. Phys. Solid State 8 (1966) 1363.

[163] Burrill, J. T., King, W. J., Harrison, S., McNally, P., IEEE Trans. Electron. Device ED 14 (1967) 10.

[164] Ponpon, J. P., Siffert, P., Réf. [1], p. 342.

[165] WiCHNER, R., Réf. [1], p. 243.

[166] Kirkpatrick, A. R., Minnucci, J. A., Shaughnessy, T. S., Greenwald, A. C., Réf. [2], p. 299.

[167] VARMA, R., ZWerdling, S., Réf. [2], p. 293.

[168] Muller, J. C., Ponpon, J. P., Grob, J. J. and A., Stuck, R., SifFerT, P., Réf. [3], p. 893.

[169] Takagi, T., Yamada, I., Kundri, M., Kobiyama, S., 2nd Intern. Conf. on Ion Source Vienne (1972) 790

[170] Takagi, T., J. Vac. Sci. Techn. 12 (1975) 1128.

[171] Takagi, T., Yamada, F., Sasaki, A., Réf. [2], p. 55.

[172] Kenchirohuda, Mototaka Kamoshida, J. Appl. Phys. 48 (1977) 18.

[173] Csepregi, L., Mayer, J. W., Sigmon, T. W., Appl. Phys. Lett. 29 (1976) 92.

[174] Csepregi, L., Kennedy, E. F., Lau, S. S., Mayer, J. W., Appl. Phys. Lett. 29 (1976) 645.

[175] Csepegi, L., Chu, W. K., Muller, H., Mayer, J. W., Sigmon, T. W., Radiat. Eff. 28 (1976) 227.
[176] Krynicki, J., SUSKI, J., UGNIEWSKI, S., GRÖTZSChEl, R., Klabes, R., Kreissig, U., Rüdiger, J., Phys. Lett. 61A (1977) 181 .

[177] Kachurin, G. A., Bogatyrev, V. A., Romanov, S. I., SMIRnov, L. S., Ion Implantation in Semiconductors, ed. F. Chernow, J. A., Borders, D. Brice, p. 445.

[178] Kachurin, G. A., Pridachin, N. B., Smirnov, L. S., Sov. Phys. Semicond. 9 (1976) 946.

[179] Shtyrkov, E. I., Khaibullin, I. B., Zaripov, M. M., GalyaTudinov, M. F., Bayazitov, R., Sov. Phys. Semicond. 9 (1976) 1309.

[180] Antonenko, A. K., Gerasimenko, N. N., DvurechenskiI, A. V., Smirnov, L. S., Tseitlin, G. M., Sov. Phys. Semicond. 10 (1976) 81.

[181] Kutukova, O. G., Strel'tsov, L. N., Sov. Phys. Semicond. 10 (1976) 265.

[182] Bolotov, V. V., Pridachin, N. B., Smirnov, L. S., Sov. Phys. Semicond. 10 (1976) 338.

[183] Bogatyrev, V. A., Gavrilov, A. A., Kachrin, G. A., Smirnov, L. S., Sov. Phys. Semicond. 10 (1976) 826.

[184] Kachurin, G. A., Nidaev, E. V., Khodyachikh, A. V., Kovaleva, L. A., Sov. Phys. Semicond. 10 (1976) 1128.

[185] Khaibullin, I. B., Shtykov, E. I., Zäipov, M. M., GalyautDinov, M. F., Zakirov, G. G., Sov. Phys. Semicond. 11 (1977) 190.

[186] Bogatyrev, V. A., Kachurin, G. A., Sov. Phys. Semicond. 11 (1977) 56.

[187] Kachurin, G. A., Nideav, E. V., Sov. Phys. Semicond. 11 (1977) 350 .

[188] Geiler, H. D., Götz, G., Klinge, K. D., Triem, N., Phys. Status Solidi 41a (1977) K 171.

[189] Young, R. T., White, C. W., Clark, G. J., Narayan, J., Christie, W. H., Murakami, M., King, P. W., Kramer, S. D., Appl. Phys. Lett. 32 (1978) 139.

[190] Young, R. T., White, C. W., Clark, G. J., Narayan, J., Westbrook, R. D., Réf. [3], p. 861.

[191] Muller, J. C., Grob, A. et J. J., Stuck, R., Siffert, P., Appl. Phys. Lett. 33 (1978) 287.

[192] MAGID, L., Réf. [4], p. 81.

[193] Michel, J., Réf. [5], p. 133.

[194] Godlewski, M., Brandhorst, H., NASA Tech. Memorandum X-3326 (1975) 213.

[195] Soclof, S., Iles, P., NASA Techn. Memorandum X-3326 (1975) 209.

[196] CARD, H. C., YANG, E. S., IEEE ED 24 (1977) 397.

[197] Muller, J. C., Siffert, P., à paraître IEEE Washington (1978).

[198] Chabbal, R., Rodot, M., Réf. [3], p. 30. 